\title{
Numerical and analytical investigation of internal slab-column connections subject to cyclic loading
}

\section{Andri Setiawan}

$\mathrm{PhD}$ candidate, Department of Civil and Environmental Engineering, Imperial College London, London, United Kingdom

\section{Robert L Vollum}

Reader in Concrete Structures, Department of Civil and Environmental Engineering, Imperial College London, London, United Kingdom

\section{Lorenzo Macorini}

Senior Lecturer in Structural Engineering, Department of Civil and Environmental Engineering, Imperial College London, London, United Kingdom

\begin{abstract}
Properly designed flat slab to column connections can perform satisfactorily under seismic loading. Satisfactory performance is dependent on slab column connections being able to withstand the imposed drift while continuing to resist the imposed gravity loads. Particularly at risk are pre 1970's flat slab to column connections without integrity reinforcement passing through the column. Current design provisions for punching shear under seismic loading are largely empirical and based on laboratory tests of thin slabs not representative of practice. This paper uses nonlinear finite element analysis (NLFEA) with ATENA and the Critical Shear Crack Theory (CSCT) to investigate the behaviour of internal slabcolumn connections without shear reinforcement subject to seismic loading. NLFEA is used to investigate cyclic degradation which reduces connection stiffness, unbalanced moment capacity, and ductility. As observed experimentally, cyclic degradation in the NLFEA is shown to be associated with accumulation of plastic strain in the flexural reinforcement bars which hinders concrete crack closure. Although the NLFEA produces reasonable strength and ductility predictions, it is unable to replicate the pinching effect. It is also too complex and time consuming to serve as a practical design tool. Therefore, a simple analytical design method is proposed which is based on the CSCT. The strength and limiting drift predictions of the proposed method are shown to mainly depend on slab depth (size effect) and flexural reinforcement ratio which is not reflected in available empirically-based models which appear to overestimate the drift capacity of slab-column connections with dimensions representative of practice.
\end{abstract}

\footnotetext{
Notation

$b_{0}$

length of control perimeter (with rounded corners) at a distance of half the average flexural effective depth from the column face

$b_{0, e} \quad$ length of effective control perimeter (with rounded corners) considering the reduction due to non-uniform shear stress distribution

$b_{0(r e c)} \quad$ length of control perimeter (with the same shape as the column) at a distance of half the average flexural effective depth from the column face

$b_{s} \quad$ width of support strip for calculating average moment per unit length
} 


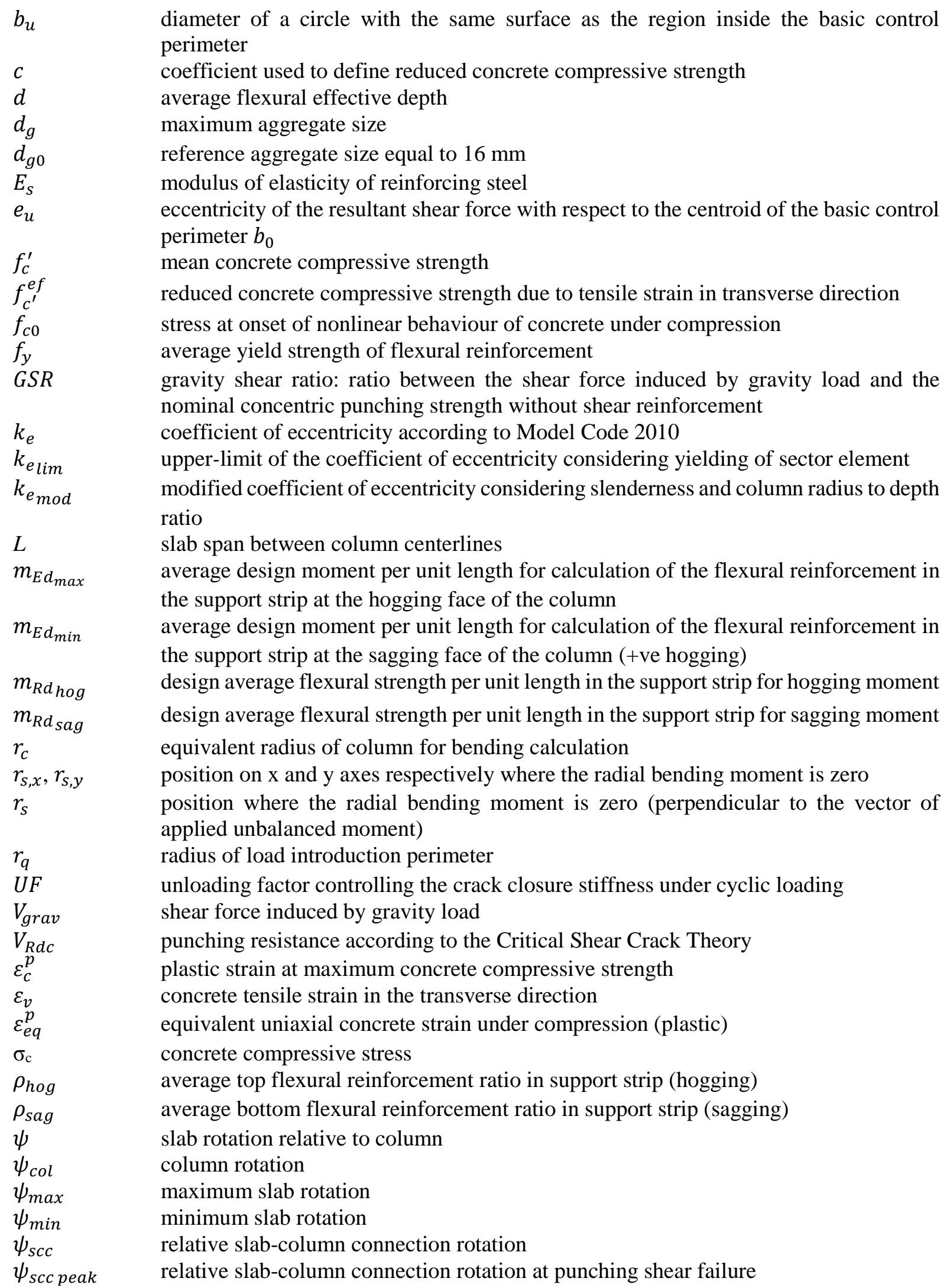




\section{Introduction}

Reinforced concrete flat slabs are commonly used in building structures for practical reasons including ease of construction, minimum floor-to-floor height, and flat soffit. Flat slabs can perform satisfactorily in earthquakes if lateral sway is limited by a primary lateral-force-resisting-system (LFRS). However, older flat slab buildings, particularly those designed to pre 1971 revisions of ACI 318, are particularly susceptible to damage during seismic events due to the absence of integrity reinforcement. For example in the 1985 Mexico City earthquake, it was reported that at least 91 flat slab buildings collapsed due to punching failure [1]. More recently, most flat slab buildings throughout the southern California were severely damaged in the 1994 Northridge earthquake [2]. Events like these have prompted much research into the punching resistance of flat slabs under seismic loading. Design guidance for seismically loaded flat slab buildings is given in ACI 318-14 [3] but not Eurocode 8 [4]. ACI 318 permits the use of flat slabs in seismic regions provided perimeter moment frames, or bracing are provided to act as the LFRS. In this case, although not designated as part of the seismic force resisting system, the flat slab system undergoes the same lateral deformation as the primary LFRS during seismic excitation. Consequently, slab-column connections have to possess sufficient ductility to attain the drift demand prior to punching failure. Laboratory tests show that the level of ductility possessed by slabcolumn connections is significantly influenced by the gravity shear ratio (GSR) which is the ratio between the shear force induced by gravity load $\left(V_{\text {grav }}\right)$ and the nominal concentric punching strength without shear reinforcement. In this paper, the GSR is defined according to ACI 318-14 [3] as:

$$
G S R=\frac{V_{\text {grav }}}{\frac{1}{3} \sqrt{f_{c}^{\prime}} \cdot b_{0(r e c)} \cdot d} \operatorname{SI~units~}(N, m m)(1)
$$

where $V_{\text {grav }}$ is the shear force induced by the gravity load, $f_{c}$ ' is the concrete compressive strength, $d$ is the average flexural effective depth, and $b_{0(\text { rec })}$ is the length of a control perimeter (with the same shape as the column) at a distance $d / 2$ from the column face.

Previous studies established best fit relationships between mean lateral drift capacity and GSR based on regression analysis of experimental data [2, 5]. Section 18.14.5.1 of ACI 318-14 provides a similar empirical relationship for design. ACI 318 requires punching shear reinforcement to be provided if the design storey drift exceeds that specified in section 18.14.5.1. However, empirically based limitations on drift like these are questionable for practical design since they are largely based on unrepresentative scaled-down slab tests with average effective depth of around $100 \mathrm{~mm}$ and $1.0 \%$ hogging reinforcement $[6,7]$. No empirical equation can provide a rational explanation of cyclic degradation and its influencing parameters. 
This study makes use of 3D nonlinear finite element analysis (NLFEA) with ATENA [8] to examine key features of the response of laboratory tested cyclically loaded internal slab-column connections without shear reinforcement. The authors are unaware of any comparable 3D NLFEA studies into the cyclic degradation of slab-column connection resistance. The NLFEA provides rational insights into the causes of cyclic degradation and the parameters that influence it but is unable to capture the observed pinching effect. The presented NLFEA is also extremely computationally demanding for cyclic loading. In view of these considerations, it is suggested that the critical shear crack (CSCT) [9] forms a more practical basis for the development of practical design recommendations for modelling punching shear failure under cyclic loading. The second half of the paper presents a simple analytical procedure, based on the critical shear crack theory (CSCT) [9], for assessing punching resistance of internal flat slabcolumn connections without shear reinforcement under cyclic loading. The proposed method has the advantage of being mechanically based yet relatively simple to use. Since it is mechanically based, the proposed model can be used to investigate the influence on slab-column connection performance of variables and combinations of variables not considered systematically in laboratory tests (e.g. slab slenderness, slab effective depth, column size). This is not possible with empirical design methods like that of ACI 318-14 which is based on regression analysis of test results from thin slabs unrepresentative of practice. The proposed method is validated with available experimental data and comparisons are made with the predictions of other methods, both analytical and empirical. Finally, the proposed method is used to derive a code-like curve relating GSR to the lateral drift limit. The predictions of the proposed method are shown to compare favourably with those of the much more complex model of Drakatos et al. model [7]. Unlike ACI 318-14 [3], but like Broms [6] and Drakatos et al. [7], the proposed model predicts that the drift at peak unbalanced moment reduces with increasing slab thickness.

\section{Nonlinear finite element analysis}

\subsection{Introduction}

A numerical model was developed in ATENA [8] for modelling punching failure under cyclic loading. The model is validated in this paper using five matching pairs of full-scaled slabs tested by Drakatos et al. [10] under monotonic and cyclic loading, as well as slab L0.5 of Tian et al. [11]. The first test series [10] provides detailed information on crack patterns and local slab sector rotations while [11] gives detailed reinforcement strains. The experimental setups used in [10] and [11] are shown in Figures 1(a) and $\mathbf{1}(\mathbf{b})$ respectively. The vertical load was applied to the column in the setup of Figure 1(b) which is classified as test setup $\mathrm{C}$ in [7]. 


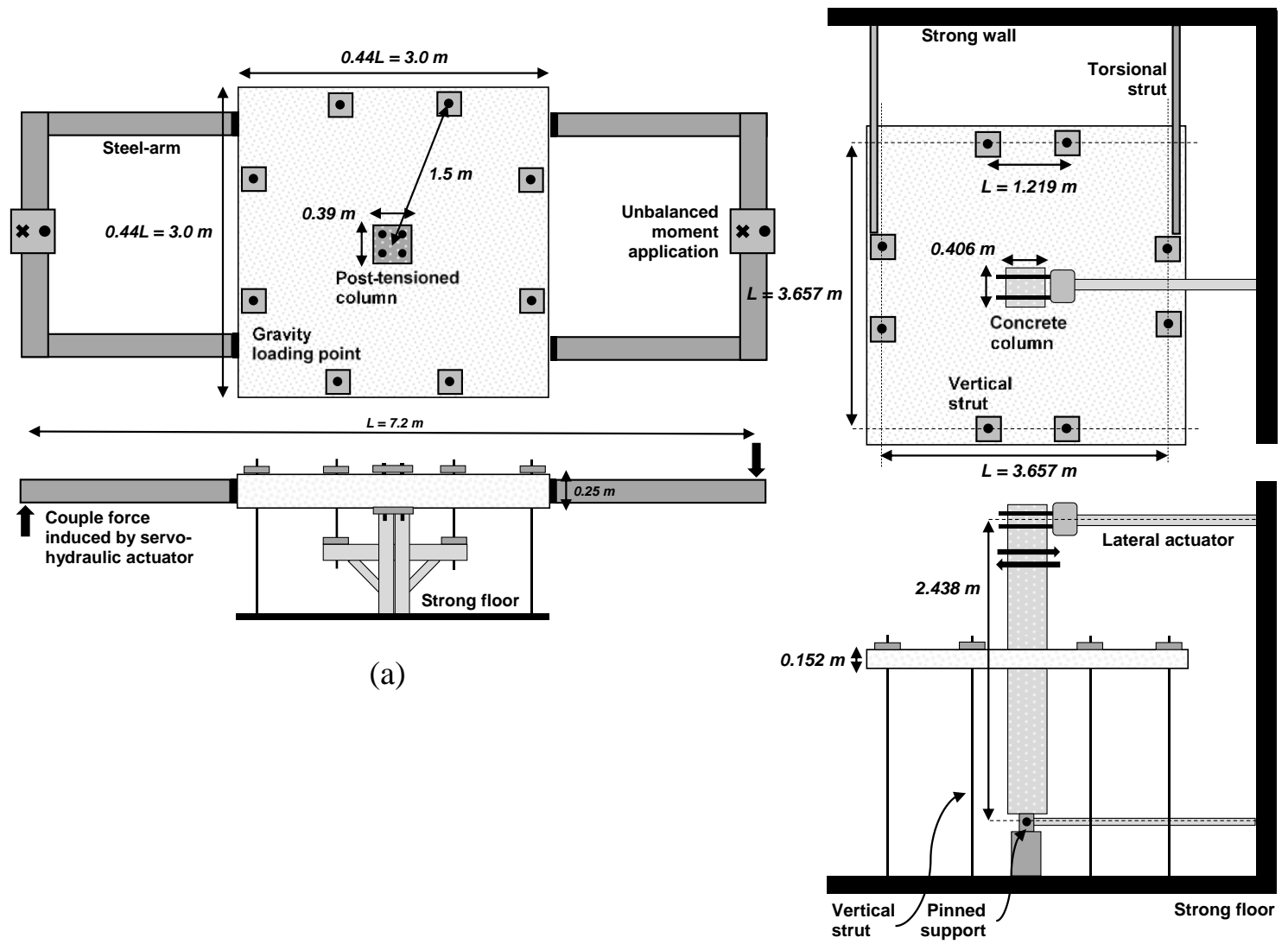

(b)

Figure 1. Illustration of experimental test setup used by: (a) Drakatos et al. [10]; (b) Tian et al. [11]

The central support plate was $390 \mathrm{~mm}$ square in [10] and $406 \mathrm{~mm}$ square in test L0.5 [11]. Table 1 summarises the material properties and geometry of the slab specimens used for the validation. Further details are given in Table A1. 
Table 1. Summary of properties of slab specimens used for NLFEA validation

\begin{tabular}{|c|c|c|c|c|c|c|c|c|c|c|c|}
\hline No. & Slab & Source & $\begin{array}{c}\text { Type } \\
\text { of } \\
\text { test* }\end{array}$ & GSR & $\begin{array}{c}f_{c} \\
(\mathbf{M P a})\end{array}$ & $\begin{array}{c}d_{g} \\
(\mathrm{~mm})\end{array}$ & $f_{y}(\mathrm{MPa})$ & $\begin{array}{l}\rho h o g \\
(\%)\end{array}$ & $\begin{array}{l}\rho_{\text {sag }} \\
(\%)\end{array}$ & $\begin{array}{c}d \\
(\mathbf{m m})\end{array}$ & $\begin{array}{c}\text { Slab } \\
\text { width } \\
\text { (m) }\end{array}$ \\
\hline 1 & PD4 & \multirow{10}{*}{$\begin{array}{c}\text { Drakatos et al. } \\
{[10]}\end{array}$} & \multirow{5}{*}{ M } & 0.41 & 39.0 & \multirow{10}{*}{16} & 507 & 0.80 & 0.35 & 201 & \multirow{10}{*}{3.00} \\
\hline 2 & PD5 & & & 0.59 & 37.5 & & 507 & 0.81 & 0.35 & 198 & \\
\hline 3 & PD3 & & & 0.86 & 34.9 & & 558 & 0.81 & 0.34 & 198 & \\
\hline 4 & PD12 & & & 0.62 & 35.5 & & 546 & 1.61 & 0.72 & 195 & \\
\hline 5 & PD10 & & & 0.90 & 32.3 & & 593 & 1.60 & 0.72 & 197 & \\
\hline 6 & PD8 & & \multirow{6}{*}{$\mathrm{C}$} & 0.46 & 32.7 & & 575 & 0.81 & 0.29 & 198 & \\
\hline 7 & PD6 & & & 0.58 & 38.3 & & 507 & 0.81 & 0.30 & 199 & \\
\hline 8 & PD2 & & & 0.86 & 36.9 & & 558 & 0.81 & 0.34 & 198 & \\
\hline 9 & PD13 & & & 0.60 & 36.5 & & 546 & 1.61 & 0.72 & 196 & \\
\hline 10 & PD11 & & & 0.90 & 33.1 & & 593 & 1.60 & 0.71 & 196 & \\
\hline 11 & L0.5 & Tian et al. [11] & & 0.23 & 25.6 & 9.5 & 469 & 0.50 & 0.25 & 127 & 3.657 \\
\hline
\end{tabular}

Notes:

$d_{g}$ is the maximum aggregate size

$f_{y}$ is the average yield strength of the flexural reinforcement bars

$\rho$ hog is the ratio of flexural reinforcement at slab tension side (hogging)

$\rho_{\text {sag }}$ is the ratio of flexural reinforcement at slab compression side (sagging)

*M indicates monotonic test; $\mathrm{C}$ indicates cyclic test

\subsection{Concrete material model (CC3DNonLinCementitious2) in ATENA}

ATENA models concrete using a smeared crack approach in conjunction with a fracture-plastic model which combines constitutive models for tensile (fracture) and compressive (plastic) behaviour. The fracture model used in this study (CC3DNonLinCementitious2) is based on the classical orthotropic smeared crack formulation and crack band model [12]. Either fixed or rotating crack models can be used in conjunction with the Rankine tensile failure criterion and exponential softening. In this study, a fully rotating-crack approach was used since it was found to simulate the experimental response more accurately than the fixed-crack model which tended to produce overly stiff load-rotation responses. Plasticity for concrete in compression is controlled by the Menetrey-William failure surface [13] which is expressed in terms of three independent stress invariants: hydrostatic stress, deviatoric stress, and deviatoric polar angle. The concrete stress-strain relationship $\left(\sigma_{\mathrm{c}}-\varepsilon_{e q}^{p}\right)$ for the ascending branch of the compressive response is expressed by the following formula:

$$
\sigma_{c}=f_{c 0}+\left(f_{c}^{\prime}-f_{c 0}\right) \sqrt{1-\left(\frac{\varepsilon_{c}^{p}-\varepsilon_{e q}^{p}}{\varepsilon_{c}^{p}}\right)^{2}}
$$


where $\sigma_{c}$ is current concrete stress for a given uniaxial equivalent strain $\varepsilon_{e q}^{p}, f_{c 0}$ is the stress at onset of concrete nonlinear behaviour under compression and $\varepsilon_{c}^{p}$ is the plastic strain at maximum compressive strength $f_{c}$.

The hardening part of the compressive response is expressed in terms of strain while the softening part is expressed in terms of displacement to introduce mesh objectivity into the finite element solution. After concrete cracks, the compressive strength in the direction parallel to the cracks is reduced similarly to the Modified Compression Field Theory [14]. However, in ATENA, this relationship is described in the form of a Gaussian which allows the user to flexibly adjust the effect. The reduced compressive strength is calculated as:

$$
f_{c^{\prime}}^{e f}=r_{c} f_{c}^{\prime}, r_{c}=c+(1-c) e^{-\left(128 \varepsilon_{v}\right)^{2}}
$$

where $f_{c^{\prime}}^{e f}$ is the reduced concrete compressive strength, $c$ defines the residual resistance, and $\varepsilon_{v}$ is the

tensile strain in the transverse direction. Under zero transverse normal strain, $f_{c^{\prime}}^{e f}$ equals the uniaxial concrete compressive strength $\left(f_{c}^{\prime}\right)$. The strength gradually reduces with strain until a minimum value, defined by the $c$ parameter, is attained. To model concrete behaviour under cyclic loading, ATENA provides a so-called Unloading Factor (UF) which controls the crack closure stiffness. UF ranges between 0 and 1 with 0 for unloading to the origin (default value for backward compatibility) and 1 for unloading parallel to the initial elastic stiffness. An initial study of cyclically-loaded specimens showed that UF mostly influences the shape of the hysteresis curve with UF=0 giving the best fit to the actual behaviour.

\subsection{Numerical methodology}

The NLFEA modelling procedure described in Section 2.2 was initially calibrated for monotonic loading with eight concentrically loaded internal slab column connections (four with varying flexural reinforcement ratios from the PG-series of Guandalini et al. [15] and four with non-axis-symmetrical reinforcement from the PT-series of Sagaseta et al. [16]). The calibration study showed that both flexural deformation and punching failure could be captured accurately using 10 linear order (8-noded) brick elements through the slab thickness in conjunction with the material parameters and solution procedure shown in Table 2 . The NLFEA accurately captured both the punching resistance (with mean and coefficient of variation of test/predicted equal to 0.983 and 0.075 ) and corresponding maximum slab rotation of these slabs (with mean and coefficient of variation of test/predicted equal to 0.964 and $0.112)$.

When modelling eccentrically loaded specimens, advantage was taken of symmetry to only model half of the specimen. This is illustrated in Figure 2 for the PD series where, for optimum element aspect 
ratio, $25 \times 25 \times 25 \mathrm{~mm}^{3}$ brick elements were used to model the slab within twice the slab effective depth $d$ of the column face (giving 10 elements through the slab thickness) while a coarser mesh $(50 \times 25 \times$ $25 \mathrm{~mm}^{3}$ and $50 \times 50 \times 25 \mathrm{~mm}^{3}$ ) was used elsewhere. The steel arms and loading plates were modelled using linear tetrahedral (4-noded) elements with elastic material. Reinforcement bars were modelled as embedded using 1D 2-noded linear truss elements. Details of the modelling of specimen L0.5 of Tian et al. [11] can be found elsewhere [17].

Perfect bond was assumed between reinforcement and concrete. Drakatos et al. [10] only report the yield strength of the reinforcement used in their tests. Examination of their tests results shows that the largest strain achieved in the cyclic tests was around 0.004-0.005. Consequently, the rebar stress-strain relationship was defined as elasto-plastic with very minimal strain hardening owing to the low maximum measured peak strain. The Bauschinger's effect was modelled using the approach of Menegotto and Pinto [18] as implemented in ATENA (with default parameters). Each specimen was meshed with 1790 linear elements, 1954 tetrahedral elements and 36980 solid (brick) elements giving a total of 44882 nodes. The external face of the top and bottom central column plates was restrained in all directions to simulate the effect of clamping the column to the slab by post tensioning.

Unbalanced moment was applied in the monotonic simulations by imposing equal and opposite vertical forces as in the tests. The experimental cyclic loading protocol [10] was complex to simulate since it prescribed the relative slab column rotation which was approximated by imposing equal and opposite vertical displacements, derived from monotonic analysis, to the loading arms. The consequence of this is discussed in Section 3. Static analysis with force-control was used for the monotonic tests along with arc-length iteration while displacement-control (Newton-Raphson) was used for the cyclic tests.

The same material inputs were used for both monotonic and cyclic loading except the compression softening limit $(c)$ given in Equation 3. This was done because comparative studies on identical monotonically loaded punching specimens unexpectedly showed displacement-control with NewtonRaphson to produce higher failures load than force-control with Arc-Length. To compensate for this, it was found necessary to reduce the compression softening limit $r_{c} f_{c}^{\prime}$ to $0.5 f_{c}^{\prime}$ (from $0.8 f_{c}^{\prime}$ for ArcLength) when using displacement-controlled loading. The convergence tolerance was set at $1 \%$ for displacement, residual, and absolute residual error and $0.1 \%$ for energy error. The key input parameters used in the analyses are summarised in Table 2 below. 


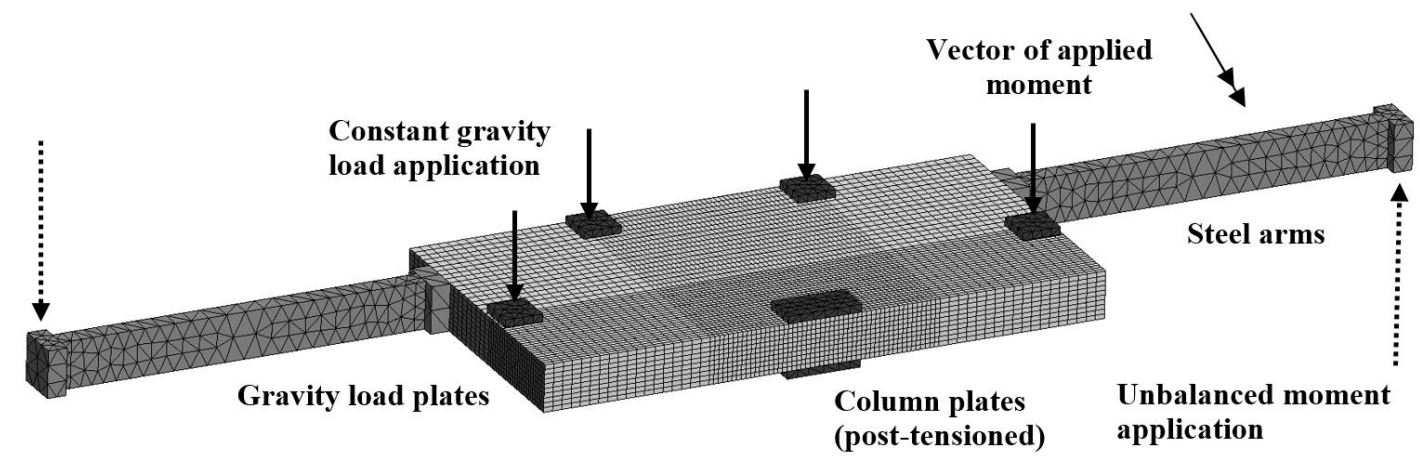

Figure 2. Geometry, boundary conditions, and meshing for slabs of Drakatos et al. [10] analysed using ATENA

\section{Table 2. Summary of material parameters and numerical input for NLFEA in ATENA}

\begin{tabular}{|c|c|c|}
\hline No. & Parameter & Value/Reference \\
\hline & Concrete constitutive model & \\
\hline A1 & Concrete elastic modulus & fib recommendation [19] \\
\hline A1 & Fracture energy & Based on Model Code 2010 [21] \\
\hline A2 & Concrete tensile strength & Based on Model Code 2010 [21] \\
\hline A3 & Smeared crack model & Fully-rotating crack \\
\hline A4 & Critical compressive displacement & $0.5 \mathrm{~mm}$ \\
\hline A5 & $\begin{array}{l}\text { Limit of compressive strength reduction due to cracking } \\
\text { (MCFT) }\end{array}$ & $0.8 f_{c}^{\prime}$ for monotonic; $0.5 f_{c}^{\prime}$ for cyclic $[14]$ \\
\hline A6 & Eccentricity (defining the shape of the failure surface) & 0.52 \\
\hline A7 & Volume dilatation plastic factor & 0 \\
\hline \multirow[t]{2}{*}{ A8 } & Unloading factor for cyclic loading & 0 \\
\hline & $\underline{\text { Reinforcement bar model }}$ & \\
\hline B1 & Stress-strain relationship & Bilinear with minimal strain hardening \\
\hline B2 & Bond-slip model & Perfect bond \\
\hline \multirow[t]{2}{*}{ B3 } & Cyclic behaviour & $\begin{array}{l}\text { Menegotto and Pinto [18] with ATENA } \\
\text { default parameters }(\mathrm{C} 1=500 ; \mathrm{C} 2=50)\end{array}$ \\
\hline & Loading procedure and convergence criteria & \\
\hline $\mathrm{C} 1$ & Loading procedure for monotonic tests & Static (force-controlled) \\
\hline $\mathrm{C} 2$ & Iteration method for monotonic tests & Arc-length method \\
\hline $\mathrm{C} 3$ & Loading procedure for cyclic tests & Static (displacement-controlled) \\
\hline $\mathrm{C} 4$ & Iteration method for cyclic tests & Newton-Raphson method \\
\hline C5 & $\begin{array}{l}\text { Convergence criteria for displacement, residual, and } \\
\text { absolute residual error }\end{array}$ & $1 \%$ \\
\hline \multirow[t]{2}{*}{ C6 } & Convergence criteria for energy error & $0.1 \%$ \\
\hline & Mesh properties & \\
\hline D1 & Mesh size (finest) & $25 \times 25 \times 25 \mathrm{~mm}$ (10 elements along height) \\
\hline D2 & Mesh element for concrete slab & 8-noded hexahedral (linear) \\
\hline D3 & Mesh element for loading apparatus & 4-noded tetrahedral (linear) \\
\hline D4 & Mesh element for reinforcement bar & 2-noded truss element (embedded) \\
\hline
\end{tabular}




\subsection{Validation results}

1) Global behaviour

Global behaviour was assessed in terms of the unbalanced moment versus relative slab-column connection rotation response. The slab-column connection rotation, $\psi_{s c c}$, is defined as:

$$
\psi_{s c c}=\frac{\psi_{\max }-\psi_{\min }}{2}-\psi_{c o l}(4)
$$

where $\psi_{\max }$ is the maximum slab rotation, $\psi_{\min }$ is the minimum slab rotation and $\psi_{c o l}$ is the column rotation which was zero in the numerical analysis since both the top and bottom column plates were fully restrained.

The rotation $\psi_{s c c}$ in actual building (continuous slabs) is related to the inter storey drift $\psi_{s t}$ as follows [7]:

$$
\psi_{s t}=\psi_{s c c}+\psi_{s o}+\psi_{c o l}(5)
$$

where $\psi_{s o}$ is the component of slab rotation due to deformation outside a radius $r_{s}=0.22 L$ of the column centreline, in which $L$ is the slab span, and $\psi_{c o l}$ is the contribution of column deformation. Drakatos et al. [7] suggest that $\psi_{s c c}$ typically contributes $75-80 \%$ of the total inter storey drift neglecting the contribution of column deformation. The punching resistance itself is related to $\psi_{s c c}$ rather than $\psi_{s t}$ since $\psi_{s o}+\psi_{c o l}$ is a global rotation which does not contribute to the critical shear crack width. Figure 3 compares the measured and calculated unbalanced moment- $\psi_{s c c}$ responses of the Drakatos et al. specimens. The NLFEA slab rotations $\psi_{\min }$ and $\psi_{\max }$ were calculated from the vertical displacements of pairs of nodes, spaced at around $200 \mathrm{~mm}$, and positioned on the slab centreline near the slab edges with minimum and maximum deflections. Rotations are presented in Figure 3 and throughout the paper in units of $\%\left(10^{2} \times\right.$ radians $)$ unless stated otherwise. 

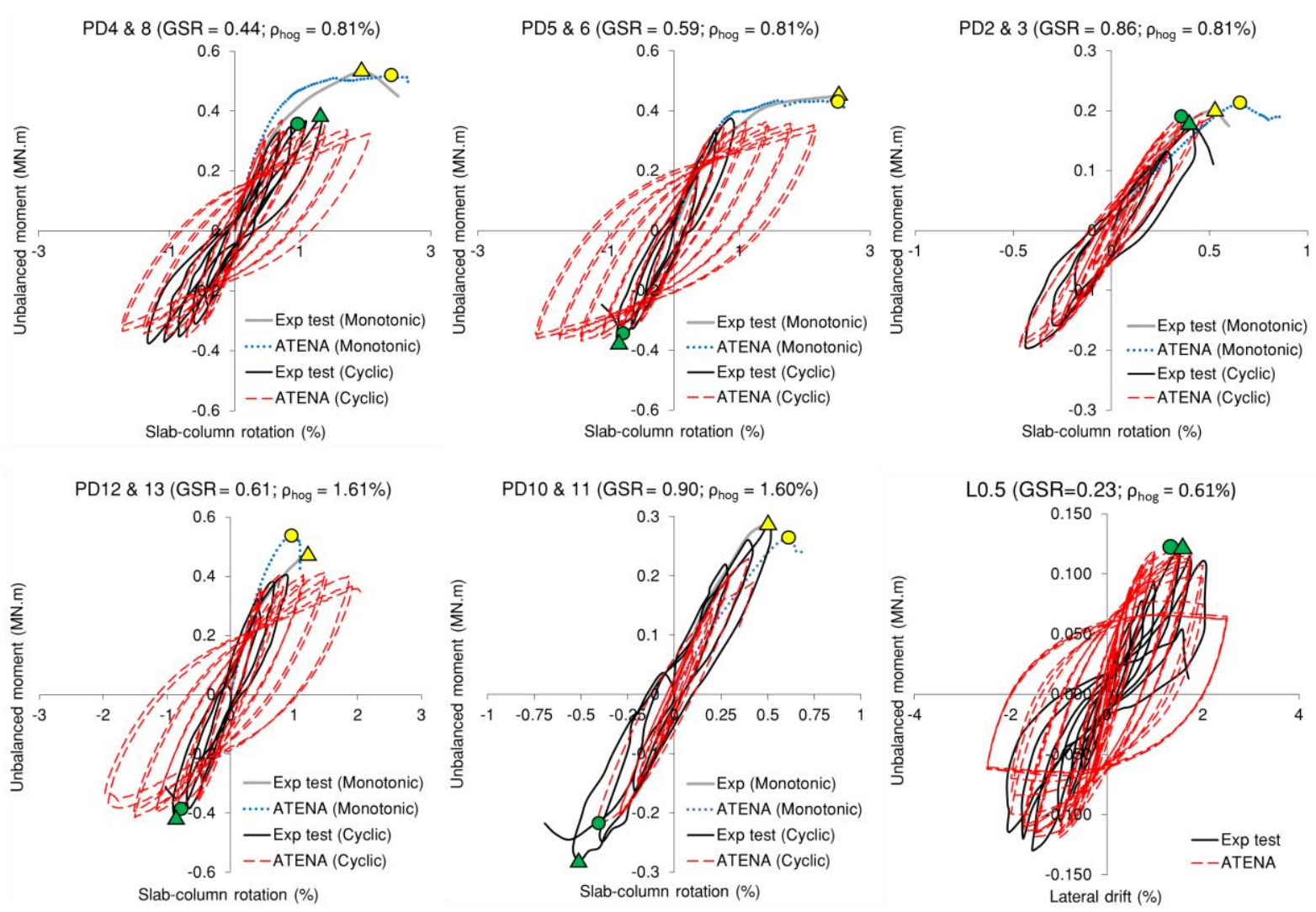

Peak unbalanced moment (M) from real test: Peak unbalanced moment $(\mathrm{C})$ from real test:

Peak arm-reaction (M) from ATENA: Peak arm-reaction (C) from ATENA:

\section{Notes: $M$ denotes monotonic; $C$ denotes cyclic}

Figure 3. Comparison of measured and predicted moment - rotation or moment - drift relationship with NLFEA

Figure 3 shows that the NLFEA predictions of $\psi_{s c c}$ are reasonable for both monotonically- and cyclically-loaded slabs. At low drift levels, ATENA overestimates the stiffness of cyclically loaded specimens due to the inability of the adopted concrete model to realistically simulate pinching behaviour. This is discussed more fully in Section 3. Comparison of the moment-rotation responses in Figure 3 for monotonically and cyclically loaded specimens shows that the NLFEA broadly captures the degradation in performance caused by cyclic loading. Under cyclic loading, the predicted unbalanced moment capacity reduces gradually subsequent to reaching its peak value, unlike the tests where loss of vertical resistance was sudden (indicated by green triangles). As done by Drakatos et al. [7], this study defines the drift at failure to be that at peak unbalanced moment. The NLFEA results in Figure 3 show the reduction of unbalanced moment and drift capacity under cyclic loading to be greatest for slabs with low GSR and/or low reinforcement ratios as observed experimentally [10]. This is because slab-column connections with low GSR and/or low reinforcement ratios typically attain larger drift prior to punching which makes them more susceptible to cyclic degradation. 


\section{2) Local behaviour}

The ability of the NLFEA to simulate local, as well as global, behaviour was validated in terms of a) slab-sector rotation; b) crack patterns and c) flexural reinforcement strain. Of these a) and b) are reported here for the PD series [10] while validation of reinforcement strains in slab L0.5 [11] can be found in [17]. Figure 4 shows the variation of local slab-sector rotation with angle measured from the axis of unbalanced moment vector for selected slabs subject to monotonic and cyclic loading. The rotations were measured at the peak unbalanced moments indicated by yellow and green circles in Figure 3 . Measured and predicted crack patterns at failure are compared in Figure 5 for selected slab specimens.

Figures 4 and 5 show that both the local slab-sector rotation and crack patterns at failure were realistically captured using NLFEA.
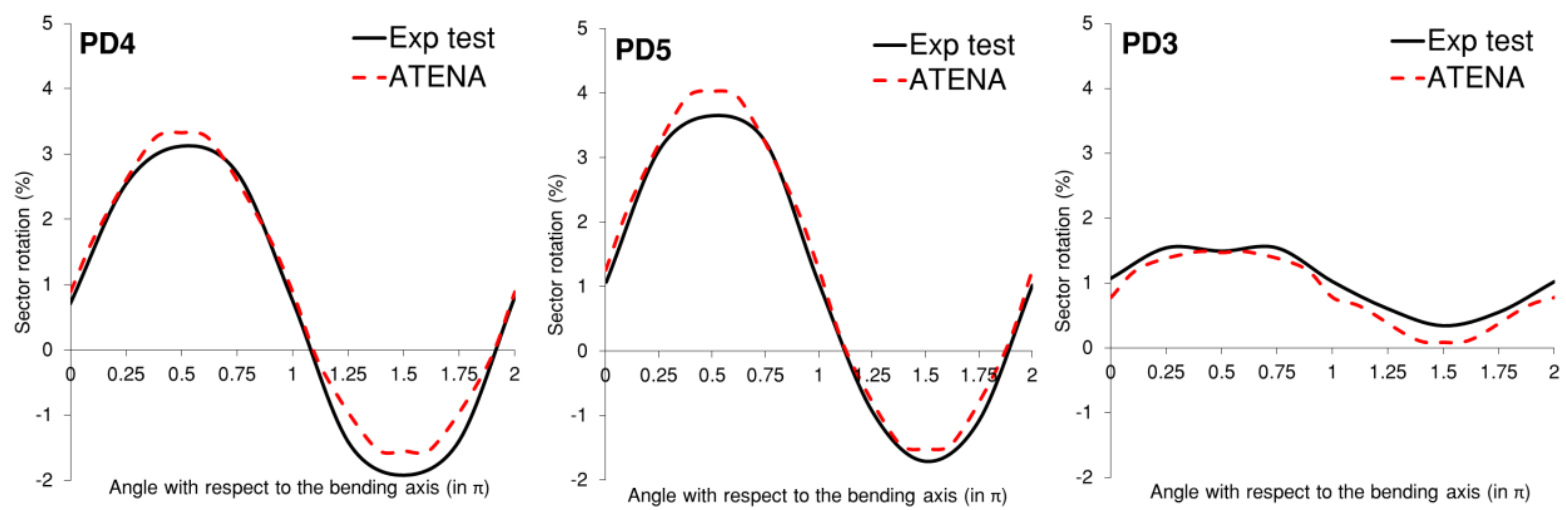

(a)
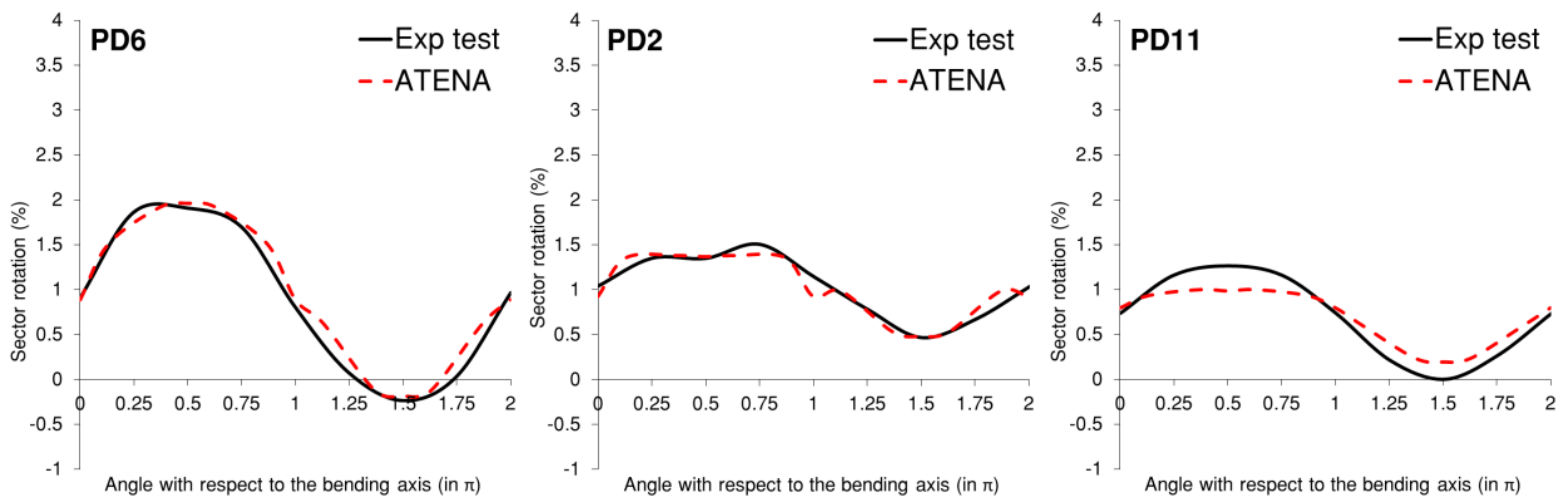

(b)

Figure 4. Comparison of measured and predicted slab-sector rotation at peak moment with NLFEA for: (a) monotonic test; (b) cyclic test 
PD3 (side-face)

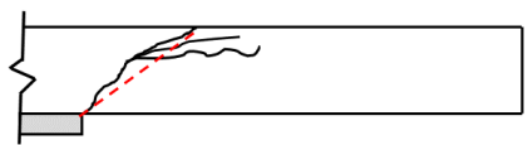

EXPERIMENTAL

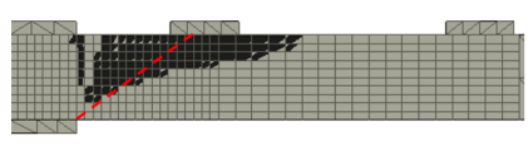

NLFEA
PD8 (top-face)
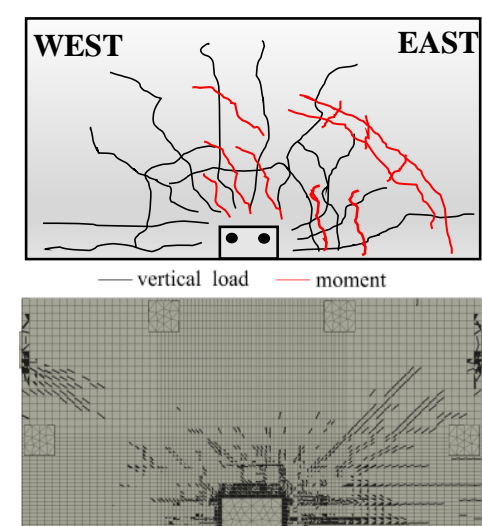

PD8 (side-face)

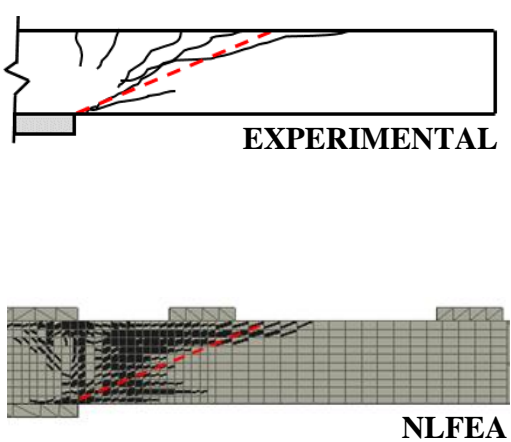

(b)

Figure 5. Comparison of measured and predicted crack patterns at failure for: (a) PD3 (monotonic); (b) PD8 (cyclic)

\section{3) Discussion of NLFEA failure criterion, loading protocol, and pinching}

Strain monitoring [17] shows that cyclic degradation of strength and stiffness is associated with progressive yielding of the flexural reinforcement bars closest to the support both experimentally and in NLFEA simulations. As drift increases, plastic strain accumulates in the rebar hindering crack closure when the loading is reversed. This condition is worsened by Bauschinger's effect which reduces the reinforcement yield strength under reversed-cyclic loading. The accumulation of plastic strain causes crack widths to increase in successive cycles. This eventually reduces shear transfer along cracks through aggregate interlock. However, it is important to remark that degradation of shear resistance along cracks was not modelled explicitly in ATENA since a rotating crack model was used. Despite this, the physical effect of loss of aggregate interlock was modelled indirectly in ATENA through its use of an equivalent plastic strain parameter. Accumulation of this strain component in the inelastic phase causes concrete to enter the compression softening regime (crushing) more rapidly under cyclic than monotonic loading. Damage is also enhanced under cyclic loading since the compressive response is adversely affected by damage in tension and vice versa.

Although broadly able to capture the experimentally observed cyclic degradation, the NLFEA overestimated the initial stiffness of cyclically loaded specimens and failed to realistically simulate pinching. The inability of the NLFEA to capture the experimentally observed response is largely due to shortcomings in the adopted concrete model but minor errors arise from differences in cyclic loading protocols. In the laboratory, one end of the steel loading frame was loaded in displacement control with load control adopted at the other end to provide an equal and opposite force. This was not possible in the NLFEA where equal and opposite displacements were applied to the loading arms. This resulted in the downwards force being marginally smaller than the upwards force at any given displacement. This reduced the designated GSR by $5-10 \%$ at peak moment unlike in the laboratory tests where the GSR remained constant during cyclic loading. Secondly, the experimental loading protocol was expressed in 
terms of $\psi_{s c c}$. This also caused modelling difficulties since the relationship between displacements at the ends of the steel arms and $\psi_{s c c}$ is unknown prior to the analysis. The adopted relationship between arm displacement and $\psi_{s c c}$ was derived from monotonic analysis. Figure $\mathbf{3}$ shows that the resulting rotations $\psi_{s c c}$ are reasonable.

As shown in Figure 3, the adopted CC3DNonLinCementitious2 concrete model is unable to simulate pinching. Since pinching is not captured, the peak unbalanced moment increases between successive cycles at the same rotation level as shown by the red and yellow dots in Figure 6 where two load cycles were applied at each rotation level as in the tests of Drakatos et al. [10]. The increase in moment between successive cycles at the same rotation explains why the numerical cyclic response in Figure 3 is stiffer at low drift levels than the corresponding monotonic response. At higher drift levels, the stiffness of the numerical cyclic response degrades relative to the monotonic response since accumulation of equivalent plastic strain is more dominant than neglect of pinching. The inability of CC3DNonLinCementitious2 to simulate pinching also causes energy dissipation to be overestimated as evident in Figure 3.

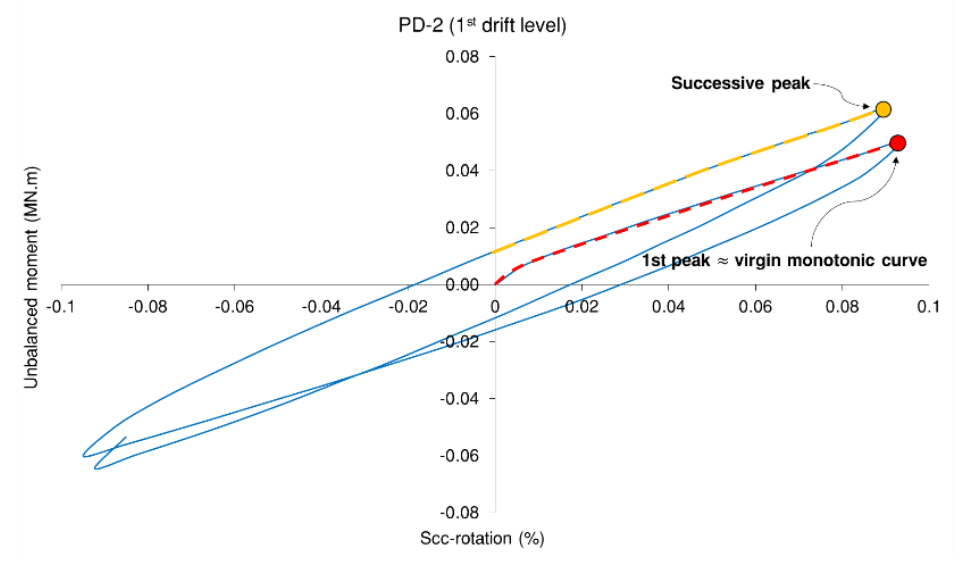

Figure 6. Moment-rotation response of specimen PD2 acquired using ATENA at $0.1 \% \psi_{\text {scc- }}$ rotation level.

\section{Proposed analytical method for cyclic punching}

\subsection{Introduction}

NLFEA with solid elements is overly complex and computationally demanding for practical design. However, NLFEA can be used to systematically explore the influence and interaction of parameters not fully explored experimentally (e.g. slab depth, slab slenderness, column size and shape etc.). For example, the presented NLFEA, although not perfect, demonstrates that cyclic degradation depends on flexural reinforcement ratio as well as GSR (see Figure 3). This complexity of behaviour demonstrates the need for mechanically based design models rather than empirically based design formulae such as that of ACI 318 [3] which only considers the influence of GSR on drift limit. The remainder of the paper proposes a simple yet mechanically-based model for practical design. Some of the modelling 
assumptions are justified with NLFEA. The method adopts the failure criterion of the CSCT [9] which calculates the shear resistance provided by concrete as follows:

$$
\left.\frac{V_{R d c}}{b_{0, e} \cdot d \cdot \sqrt{f_{c}^{\prime}}}=\frac{0.75}{1+15 \frac{\psi \cdot d}{d_{g 0}+d_{g}}}(6) \quad \text { (SI units; } N, m m\right)
$$

where $V_{R d c}(\mathrm{~N})$ is the punching load capacity according to the CSCT, $b_{0, e}$ is the effective perimeter of the critical section at $d / 2$ from the column face (rounded corners), $\psi$ is the slab rotation (radians), and $d_{g 0}$ is a reference aggregate size equal to $16 \mathrm{~mm}$.

The shear resistance depends on the slab rotation $(\psi)$ and the level of eccentricity which increases the maximum slab rotation as well the maximum shear stress. Under eccentric loading, the shear resistance calculated with Equation 6 varies around the control perimeter since eccentricity causes the slab rotation to vary sinusoidally as shown in Figure 4. Drakatos et al. [7] addressed this issue by integrating both shear forces and shear resistances around the control perimeter. In order to perform the integration, the slab is firstly divided into a number of sector elements around the tangential axis of the so-called the sector model of Kinnunen and Nylander [20]. At each load step, a new value of $\psi_{\max }$ is selected and the internal forces are determined for each individual sector element from consideration of shear and moment equilibrium in terms of $\psi_{\min }$ which is iterated until the sum of the resulting shear forces acting on each sector element equals the applied shear force. Drakatos et al. [7] assumed that shear failure occurs in cyclically loaded slabs when the sector subjected to the largest slab rotation reaches the CSCTfailure criterion. This failure criterion is also adopted in MC2010 but as shown by Drakatos et al. [7] is overly conservative for monotonically loaded slabs where shear redistribution around the control perimeter delays failure.

\subsection{Formulation of proposed method}

This study presents a simplified procedure which avoids the need to consider equilibrium of individual sector elements as done by Drakatos et al. [7]. The method is an extension of Level of Approximation II (LoA II) in fib Model Code 2010 [21] which provides a simple equation for calculating the maximum slab rotation under eccentric loading. MC2010 also reduces the length of the basic control perimeter $\left(b_{0}\right)$ by a multiple $\left(k_{e}\right)$ to account the non-uniform shear force distribution induced by moment transfer between the slab and the supported area. The effective control perimeter $b_{0, e}=k_{e} b_{0}$ in which the coefficient $k_{e}$ can be estimated as:

$$
k_{e}=\frac{1}{1+\frac{e_{u}}{b_{u}}}(7)
$$


where $e_{u}$ is the eccentricity of the resultant of shear force with respect to the centroid of the basic control perimeter and $b_{u}$ is the diameter of a circle with the same surface as the region inside the basic control perimeter.

The method proposed here for cyclically loaded slabs involves a modification to the MC2010 LoA II procedure for calculation of slab rotation as well as a refinement of $k_{e}$ as described below.

\section{1) Moment-rotation relationship}

Acquiring a sufficiently accurate moment-rotation relationship is crucial for assessment with the CSCT since it relates punching resistance to slab rotation. However, defining a sector model and formulating equilibrium at both sector and global levels is overly complex for normal design. In the present study, the maximum rotation is calculated in accordance with MC2010 LoA II as follows (all units SI; N, mm, radians):

$$
\begin{gathered}
\psi_{\text {max }}=1.5 \cdot \frac{r_{s}}{d} \cdot \frac{f_{y}}{E_{s}} \cdot\left(\frac{m_{E d_{\text {max }}}}{m_{R d_{\text {hog }}}}\right)^{1.5} \\
m_{E d_{\text {max }}}=V_{\text {grav }} \cdot\left(\frac{1}{8}+\frac{\left|e_{u}\right|}{2 . b_{s}}\right) \\
b_{s}=1.5 \cdot \sqrt{r_{s, x} \cdot r_{s, y}} \\
m_{R d_{h o g}}=\rho_{\text {hog }} \cdot f_{y} \cdot d^{2} \cdot\left(1-\frac{\rho_{h o g} \cdot f_{y}}{2 \cdot f_{c}{ }^{\prime}}\right)
\end{gathered}
$$

where $m_{E d_{\max }}$ is the maximum average moment per unit length $(\mathrm{Nmm} / \mathrm{mm})$ for calculation of the flexural reinforcement in the support strip at the column face, $b_{s}$ is the width of the support strip for calculating the average moment per unit length, $r_{s}$ denotes the position relative to the support axis where the radial bending moment is zero with $r_{s, x}$ and $r_{s, y}$ denoting the positions on the $\mathrm{x}$ and $\mathrm{y}$ axes respectively. For regular flat slabs where the ratio of spans $L_{x} / L_{y}$ is between 0.5 and $2.0, r_{s}$ can be approximated as $0.22 L_{x}$ or $0.22 L_{y}$ for the $\mathrm{x}$ and y directions respectively [21]. Section 4.3 defines $r_{s}=r_{s, x}=r_{s, y}$ for the test specimens considered in this paper which all had square slabs. $E_{s}\left(\mathrm{~N} / \mathrm{mm}^{2}\right)$ is the modulus of elasticity of reinforcing steel and $m_{R d h o g}(\mathrm{Nmm} / \mathrm{mm})$ is the design average flexural strength per unit length in the support strip for hogging moment (positive) (in this paper moments of resistance are calculated using the average effective depth $d$ since only isotropic reinforcement is considered).

Although the punching resistance of cyclically loaded slabs is assumed to depend on the maximum rotation as in [7], the minimum rotation is needed to calculate the slab-column connection rotation $\left(\psi_{s c c}\right)$ (see equation 4) and hence global inter-storey drift. MC2010 gives no guidance on the calculation of $\psi_{\min }$ since it is not relevant to the design of monotonically loaded connections. The proposed calculation procedure for $\psi_{\min }$, depends on the sign of $m_{E d_{\min }}$ (analogous to $m_{E d_{\max }}$ ) which determines whether 
hogging or sagging reinforcement is activated at the column face supporting the slab sector rotating $\psi_{\min }$. For positive $m_{E d_{\min }}, \psi_{\min }$ (radians) can be estimated as:

$$
\psi_{\min (+)}=1.5 \cdot \frac{r_{s}}{d} \cdot \frac{f_{y}}{E_{s}} \cdot\left(\frac{m_{E d_{\min }}}{m_{R d_{\text {hog }}}}\right)^{1.5}
$$

where $m_{E d_{\text {min }}}(\mathrm{Nmm} / \mathrm{mm})$ is given by:

$$
m_{E d_{\text {min }}}=V_{\text {grav }} \cdot\left(\frac{1}{8}-\frac{\left|e_{u}\right|}{2 \cdot b_{s}}\right)
$$

For negative $m_{E d_{\min }}, \psi_{\min }$ can be estimated as:

$$
\psi_{\min (-)}=-1.5 \cdot \frac{r_{s}}{d} \cdot \frac{f_{y}}{E_{s}} \cdot\left(\frac{\left|m_{E d_{\text {min }}}\right|}{m_{R d_{s a g}}}\right)^{1.5}
$$

where $m_{R d_{s a g}}$ is the design average flexural strength per unit length $(\mathrm{Nmm} / \mathrm{mm})$ in the support strip for sagging moment which is given by:

$$
m_{R d_{\text {sag }}}=\rho_{\text {sag }} \cdot f_{y} \cdot d^{2} \cdot\left(1-\frac{\rho_{\text {sag }} \cdot f_{y}}{2 \cdot f_{c}^{\prime}}\right)
$$

The reinforcement ratio $\rho_{s a g}$ should be limited to a minimum of $0.5 \rho_{\text {hog }}$ in Equation 15. Based on comparisons with test data, $m_{E d_{\text {min }}}$ in Equation 14 should be limited to $m_{R d_{s a g}}$ when calculating $\psi_{\min (-)}$. These conditions are introduced to prevent $\left|\psi_{\min (-)}\right|$, and hence $\psi_{\text {scc }}$, from becoming unrealistically large at failure.

2) Shear stress demand

In the proposed method, the basic control perimeter is reduced by a multiple $k_{e_{\text {mod }}}$ to account for the non-uniform shear distribution under eccentric cyclic loading. Studies by the authors using both the analytical procedure of Drakatos et al. [7] and NLFEA with nonlinear shell elements (not reported here) suggest that $k_{e_{m o d}}$ is directly related to the proportion of unbalanced moment resisted by eccentric shear. This proportion was found to be mostly affected by the ratio $r_{d} / r_{s}$ in which $r_{s}$ is proportional to the slab span $(L)$. A systematic investigation was performed using the model of Drakatos et al. [7] to find a correlation between $1 / k_{e_{m o d}}$ and $r_{d} / r_{s}$. In this analysis, $r_{d} / r_{s}$ was varied by independently changing $r_{s} / d$ and $r_{d} / d$ for a slab with the geometry presented in [10], while keeping other parameters unchanged. This was done since there is an interdependency between $r_{s}, r_{c}$, and $d$. Curve fitting using 
regression analysis was then performed to develop analytical expressions to describe the influences of $r_{s} / d$ and $r_{d} d d$ on $1 / k_{e_{m o d}}$ as illustrated in Figures 7(a) and (b) below.

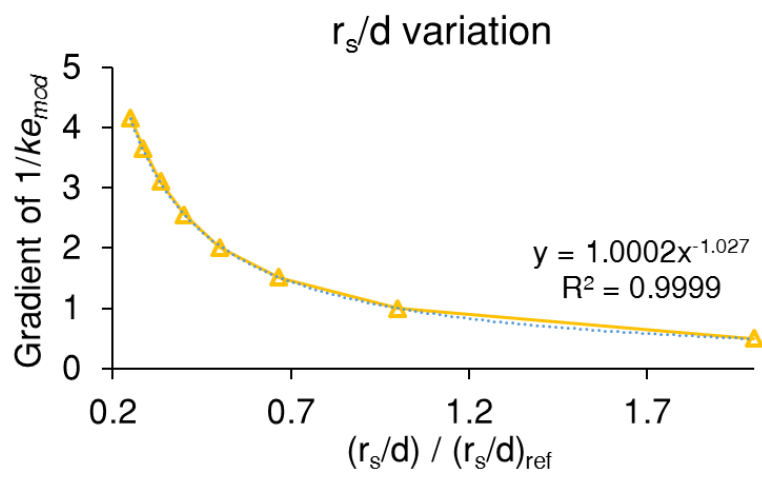

(a)

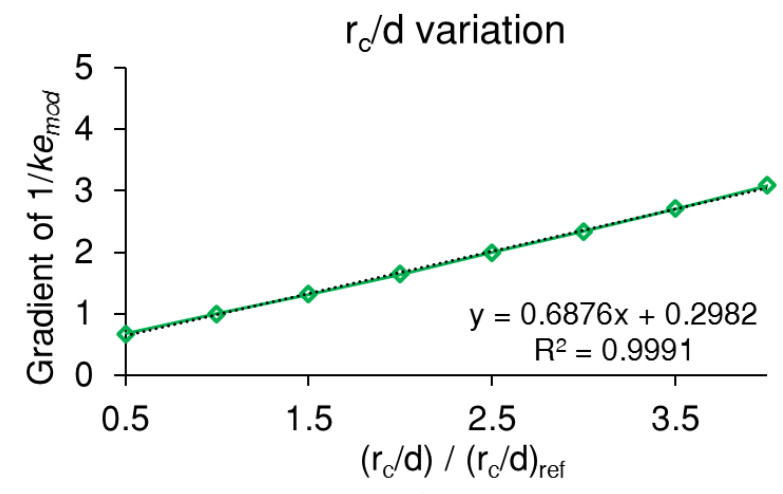

(b)

Figure 7. Derivation of modified $k_{e}$ parameter for: a) slenderness ratio; b) column radius to depth ratio

Based on the regression analysis $k_{e}$ was modified as follows:

$$
\begin{aligned}
k_{e_{\text {mod }}}= & \frac{1}{1+\left(\frac{e_{u}}{b_{u}}\right)\left\{\left[\frac{\left(r_{s} / d\right)_{\text {ref }}}{r_{s} / d}\right] *\left[0.7\left(\frac{r_{c} / d}{\left(r_{c} / d\right)_{\text {ref }}}\right)+0.3\right]\right\}}(16) \\
& \text { with }\left(r_{s} / d\right)_{\text {ref }}=6.25 ;\left(r_{c} / d\right)_{\text {ref }}=0.8125
\end{aligned}
$$

where $r_{c}$ is the column radius which is taken as half the column side length for square columns.

Additionally, the original formulation of $k_{e}$ does not consider the maximum shear stress (peak) that can develop in the sector with maximum rotation. In reality, yielding of the sector element may limit the increase of shear stress and enforce shear redistribution to adjacent sectors. In order to account for this, a lower limit to $k_{e_{m o d}}$ is introduced as follows:

$$
k_{\text {emod }} \geq k_{e_{\text {lim }}}=\frac{V_{\text {grav }}}{2 \pi \cdot r_{s} \cdot m_{\text {rd(hogging })} \cdot\left(\frac{1}{r_{q}-r_{c}}\right)}
$$

where $V_{\text {grav }}$ is the gravity load $(\mathrm{N}), r_{q}$ is the radius of the load introduction at the perimeter which is approximated as $r_{s}$ in this paper.

Equations 16 and 17 for $k_{\text {emod }}$ are applicable to cyclically loaded slabs where tests show shear redistribution of the type identified by Sagaseta et al. [16] to be negligible. Use of $k_{\text {emod }}$ is conservative for monotonically loaded slabs since their resistance is enhanced by shear redistribution which is neglected in $k_{\text {emod }}$. The influence of the term $\left[\frac{\left(r_{s} / d\right)_{\text {ref }}}{r_{s} / d}\right]$ in equation (16) is greatest for laterally loaded test specimens where the gravity load is applied to the column since $r_{s}=0.5 \mathrm{~L}$ for these slabs compared with $r_{s}=0.22 \mathrm{~L}$ for slabs subject to gravity loading. 


\subsection{Calculation of failure point}

The following step-by-step procedure can be used to predict the eccentricity at punching failure and corresponding drift:

1. Assume a value for the ultimate eccentricity $\left(e_{u}\right)$,

2. Calculate the maximum slab rotation $\left(\psi_{\max }\right)$ for the chosen $e_{u}$ using Equations 8 to 11,

3. Calculate $k_{e_{\text {mod }}}$ in terms of $e_{u}$ with Equations $\mathbf{1 6}$ and $\mathbf{1 7}$ and hence the effective control perimeter length $b_{0, e}=k_{e_{\text {mod }}} \cdot b_{0}$

4. Calculate $V_{R d c}$ using equation (6) with $b_{0, e}$ from step 3 and $\psi_{\max }$ from step 2.

5. Repeat steps 1. to 4. iterating $e_{u}$ until $V_{R d c}=V_{g r a v}$.

6. Calculate $\psi_{\min }$ using equations $\mathbf{1 2}$ to $\mathbf{1 5}$ and hence $\psi_{s c c}$.

This step-by-step procedure, which is easily implemented in a spreadsheet, is demonstrated schematically in Figure 8.

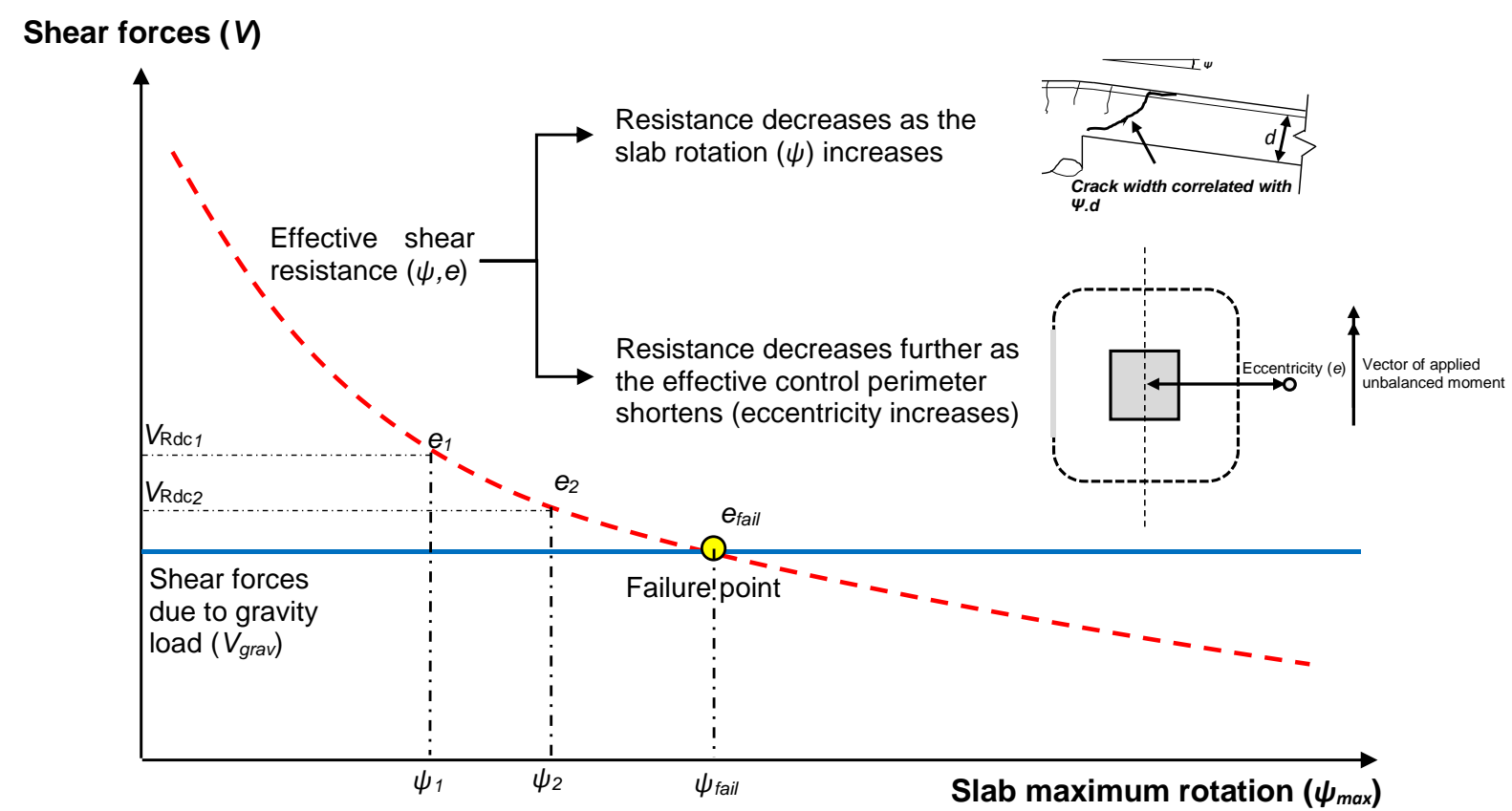

Figure 8. Schematic illustration of the proposed analytical method

As shown in Figure 8, the shear resistance decreases with increasing slab rotation and eccentricity. Failure occurs when the shear resistance reduces to the applied gravity load at the eccentricity $e_{\text {fail }}$ shown in Figure 8. The capability of the proposed analytical method to capture both the moment-rotation response and $e_{\text {fail }}$ was investigated using an experimental database.

\section{Validation of proposed analytical method}

\subsection{Initial validation of the proposed $\psi_{\min }$ and $\psi_{\text {scc }}$ formula}


The proposed modification of MC2010 LoA II to estimate $\psi_{\min }$ and $\psi_{s c c}$ was validated for the cyclicallyloaded slabs from the PD series [10] which is unique in providing $\psi_{\min }, \psi_{\max }$ and $\psi_{s c c}$. Plots of measured and predicted slab rotations are given in Figure 9 along with the authors' predictions obtained using the Drakatos et al. [7] eccentric sector model for comparison. In both analyses, the slab radius $r_{\mathrm{s}}$ was taken as half the slab side length of $3.0 \mathrm{~m}$. The stiffening influence of the threaded bars, connecting the slab edge to the steel arms, was considered by increasing the flexural reinforcement ratio as shown in Appendix A. The \% increase in reinforcement ratio was based on NLFEA studies without and with the threaded bars.
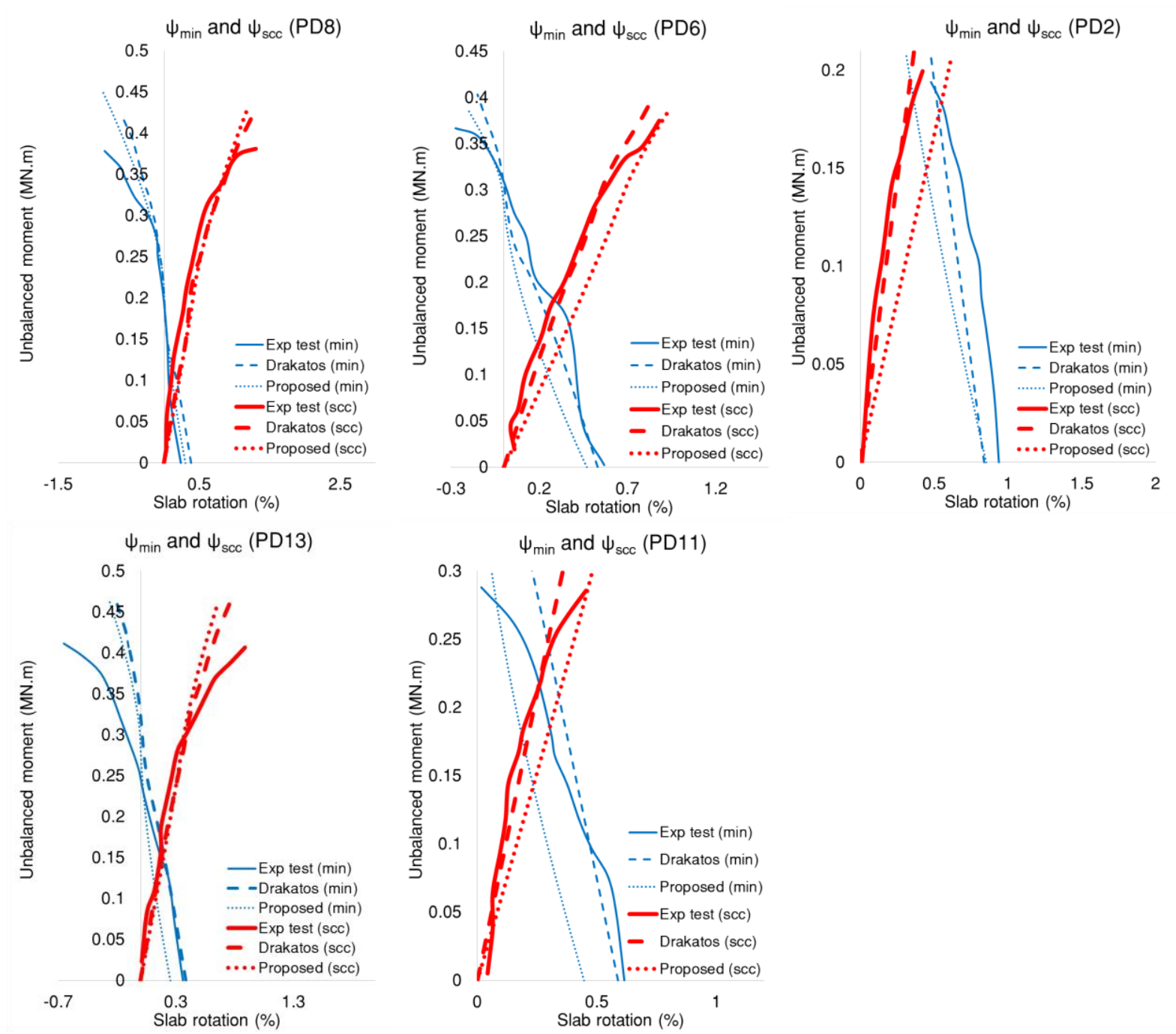

Figure 9. Measured and predicted minimum and relative slab-column rotation using the adjustment of LoA II MC2010 and Drakatos eccentric sector model [7]

Figure 9 shows that the proposed method gives good estimates of $\psi_{\min }$ and $\psi_{s c c}$ for all the considered slabs. The results obtained with the proposed method also compare favourably with those derived using the significantly more complex procedure of Drakatos et al. [7]. 
The proposed method was validated against that of Drakatos et al. [7] by comparing limiting drifts for slabs with $L / d$ equal to 20 and 34. For each $L / d$, the limiting drift was calculated with $r_{d} d d$ of $0.5,1.0$ and 1.5. The ratio $r d d$ was varied by changing the column size while keeping $d$ constant. The resulting drift predictions given by each method compare well as shown in Figure 10. The influence of "size effect" is also captured almost identically by both methods as shown in Figure 11.

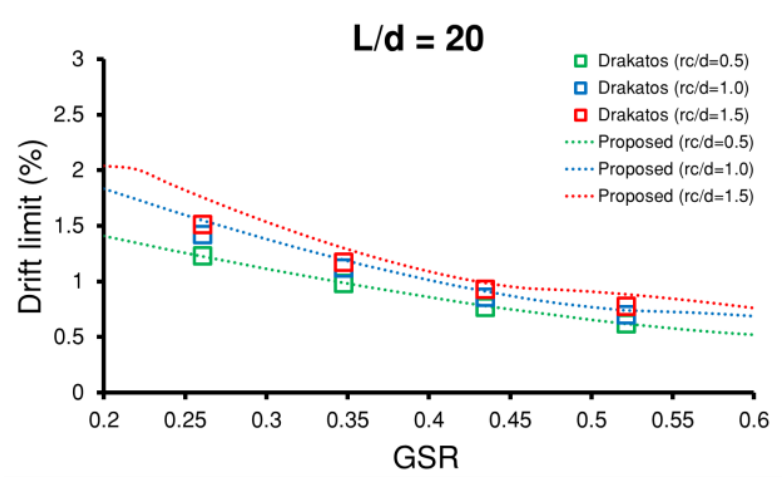

(a)

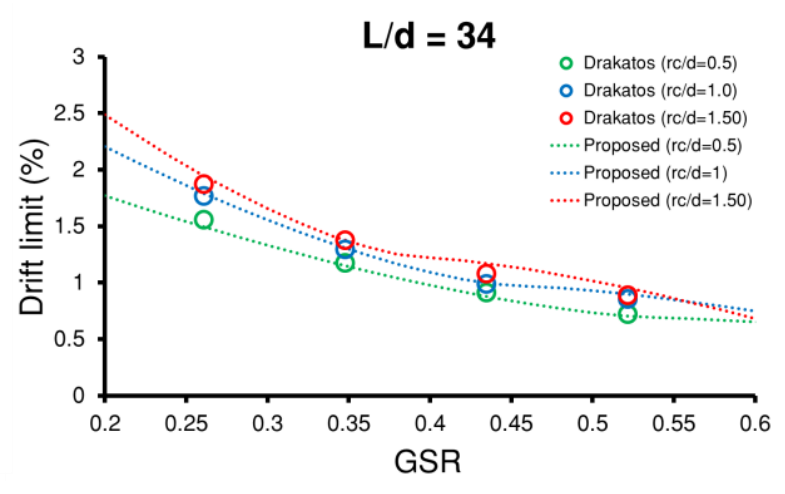

(b)

Figure 10. Comparison of drift predictions of proposed method with Drakatos method for slabs with: a) $L / d=20$; b) $L / d=34\left(d=200 \mathrm{~mm}\right.$; $\rho_{\text {hog }}=0.75 \%$; $\rho_{\text {sag }}=0.375 \%$; $f_{y}=$ $\left.550 \mathrm{MPa} ; f_{c}=32 \mathrm{MPa} ; d_{g}=16 \mathrm{~mm}\right)$

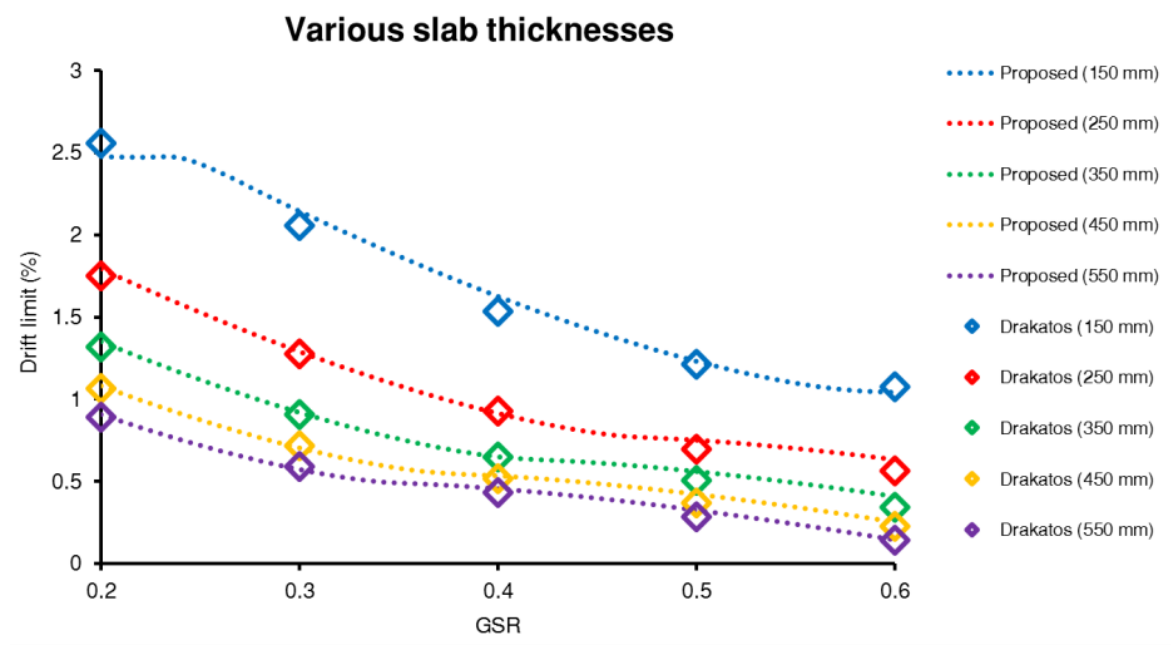

Figure 11. Comparison of drift predictions of proposed method with Drakatos method for various slab thicknesses $\left(L / d=30 ; r_{d} / d=0.975 ; \rho_{\text {hog }}=0.75 \% ; \rho_{\text {sag }}=0.375 \% ; f_{y}=\right.$ $\left.550 \mathrm{MPa} ; f_{c^{\prime}}=32 \mathrm{MPa} ; d_{g}=16 \mathrm{~mm}\right)$

\subsection{Validation of proposed method with slabs from experimental database}

The proposed method was validated with an experimental database consisting of 50 internal slabcolumn connections (isolated) without shear reinforcement subject to cyclic loading. All the specimens had square columns and were loaded with combined gravity and uniaxial lateral loading. The database 
included 33 specimens [7, 11, 22-36] from the database compiled by Drakatos [37] and 17 additional specimens [29, 38-43]. Details of the specimen geometry and material properties are given in Appendix A along with the peak moment capacities and associated rotations. Consideration of the database shows that the slenderness $(L / d)$ of the specimens varies considerably. The advantage of mechanically based design models like that of the authors' is that the specimen slenderness is accounted for in the calculation of drift. With the exception of the specimens of Drakatos et al. [10] and Almeida et al. [38], the majority of specimens were type $\mathrm{C}$ according to the classification of Drakatos et al. [7] (see Figure 1(b)). Type $\mathrm{C}$ specimens are grouped in Appendix A according to whether the vertical load (gravity) was applied to the column (C1) or slab (C2).

The radius $r_{s}$ used for calculation of rotation in the CSCT was taken as $0.22 \mathrm{~L}$ (where $\mathrm{L}$ is defined in Figure 1) for cases where the vertical load was applied to the slab (e.g. Figure 1(a)) and 0.5L for slabs with vertical load applied to the column (e.g. Figure 1(b)). Drift rather than $\psi_{s c c}$ was measured in all the tests except those of Drakatos et al. [10], Emam et al. [39] and Marzouk et al. [40].

In test setup C2, deformation of the slab outside $r_{s}=0.22 L$ contributes to drift. Drakatos et al. [7] used an effective beam method to simulate the slab outside $r_{s}=0.22 L$ but this is not considered in this paper to enable direct comparison with the authors' simplified method. To investigate the effect of this, NLFEA with ATENA was performed for slabs ND4LL, ND1C, and ND5XL [33]. Figure 12 shows the contributions to column rotation of $i$ ) the slab-column connection region (within $r_{s}=0.22 L$ ) and ii) the outer region between $r_{s}=0.22 \mathrm{~L}$ and $0.5 \mathrm{~L}$.

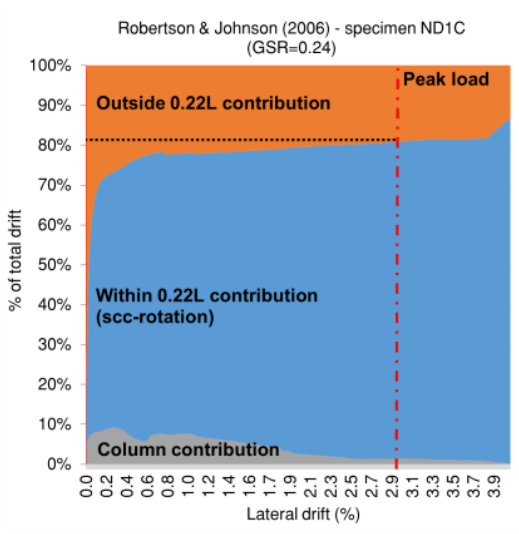

(a)

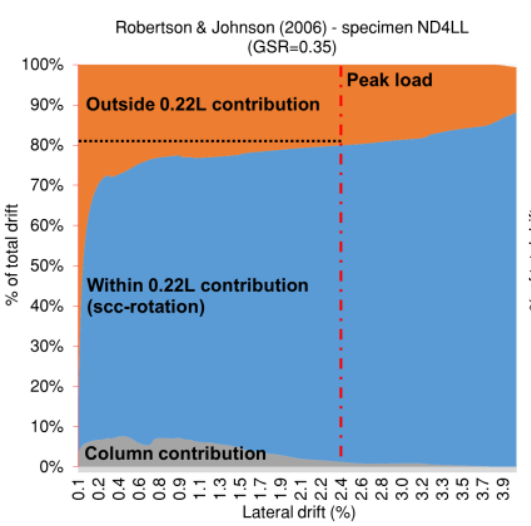

(b)

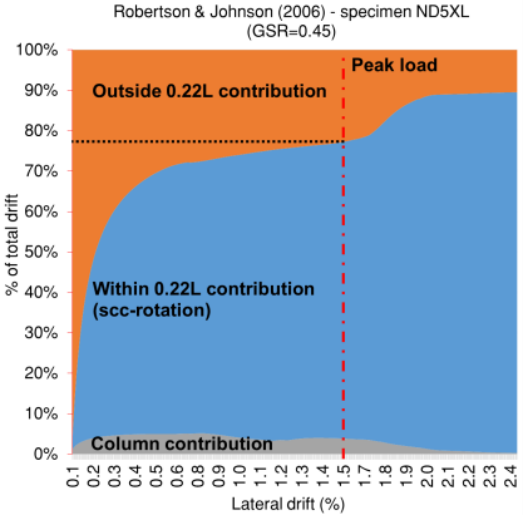

(c)

Figure 12. Contribution of column, connection region within $0.22 \mathrm{~L}$, and outer slab region between $0.22 \mathrm{~L}$ and $0.5 \mathrm{~L}$ as a function of lateral drift for slabs: a) ND1C; b) ND4LL; c) ND5XL from Robertson and Johnson [33] analysed using ATENA

Figure 12 shows that near failure the relative contribution of each component of rotation is fairly constant, and independent of GSR. Furthermore, the column contribution is almost negligible which is typical. At peak unbalanced moment, the connection region contributes around $80-85 \%$ of the total lateral drift with the slab outside $0.22 \mathrm{~L}$ contributing around $15-20 \%$. To confirm the generality of this, 
15 slabs from the database [11, 23, 24, 29, 30, 32-34, 36, 43] with test setup C2 were assessed with drift calculated as i) $\psi_{s c c}$ and ii) $\psi_{s c c} 0.85$. The results are plotted in Figure 13 which shows that drift predictions improve significantly when calculated as $\psi_{s c c} / 0.85$ (depicted "with outer") compared with $\psi_{s c c}$ (depicted "without outer")

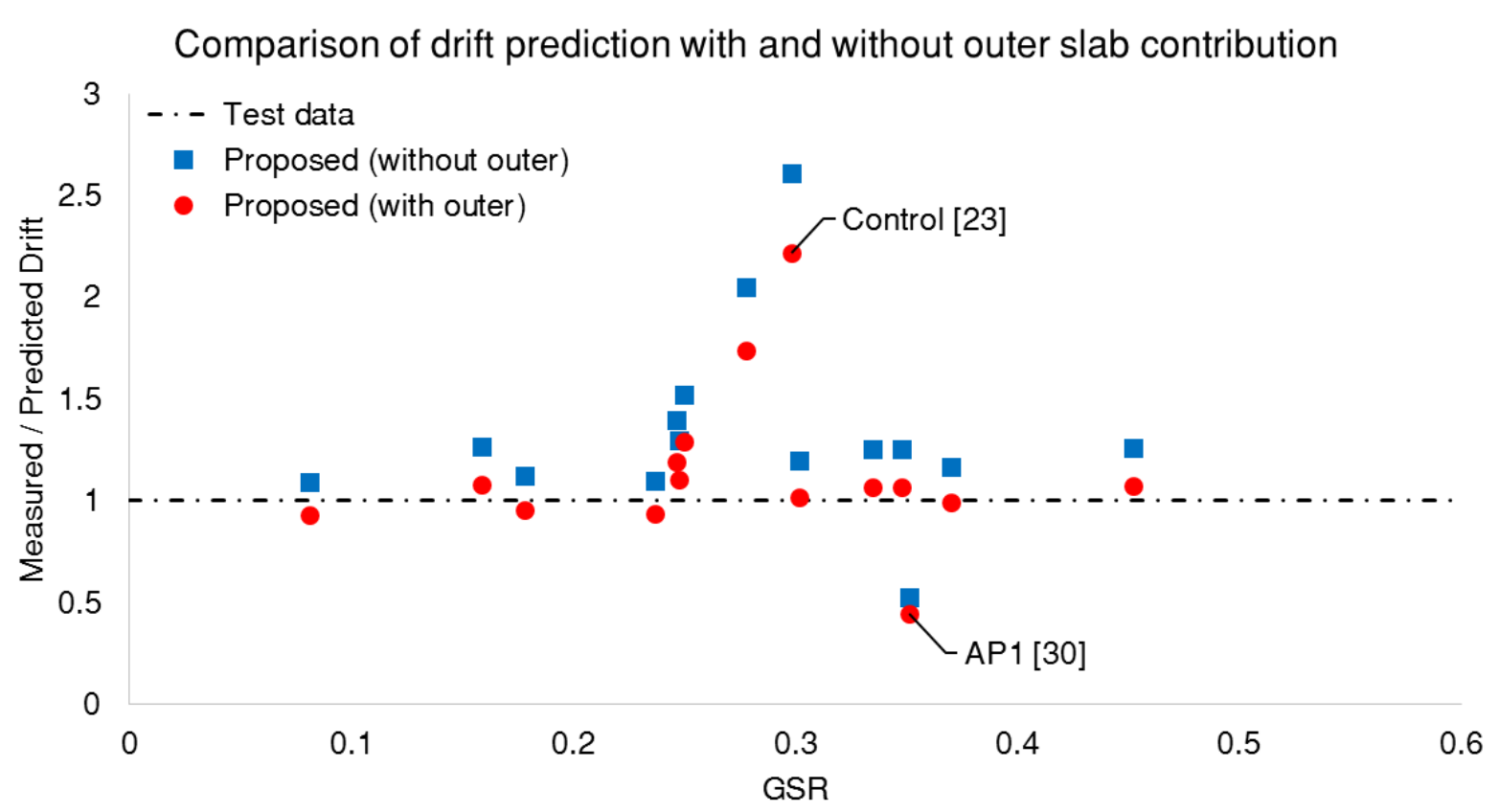

Figure 13. Measured to predicted drift at failure according to proposed method, with versus without outer slab contribution

In the analyses of the database, the lateral drift was estimated as follows for test setup C:

i) for test setup $\mathrm{C} 1$ with gravity load applied through the column, lateral drift equals $\psi_{s c c}$,

ii) for test setup $\mathrm{C} 2$ with gravity load applied through the slab, and flat slab buildings, lateral drift can be approximated as $\psi_{s c c} / 0.85$.

Representative plots of the measured and predicted unbalanced moment - drift relationship ( $\psi_{s c c}$ for slabs of Drakatos et al.), including the failure point, are shown in Figure 14 along with NLFEA results where available. Results are grouped according to the test setup with drifts in Figure 14(c) (test setup C2) calculated as $\psi_{s c c} 0.85$ as explained above. Figure 14 shows that independent of test setup the proposed method gives reasonably accurate predictions for both the moment - rotation relationship and the point of failure. Furthermore, the proposed method is comparable in accuracy with the much more complex method of Drakatos et al. [7]. 

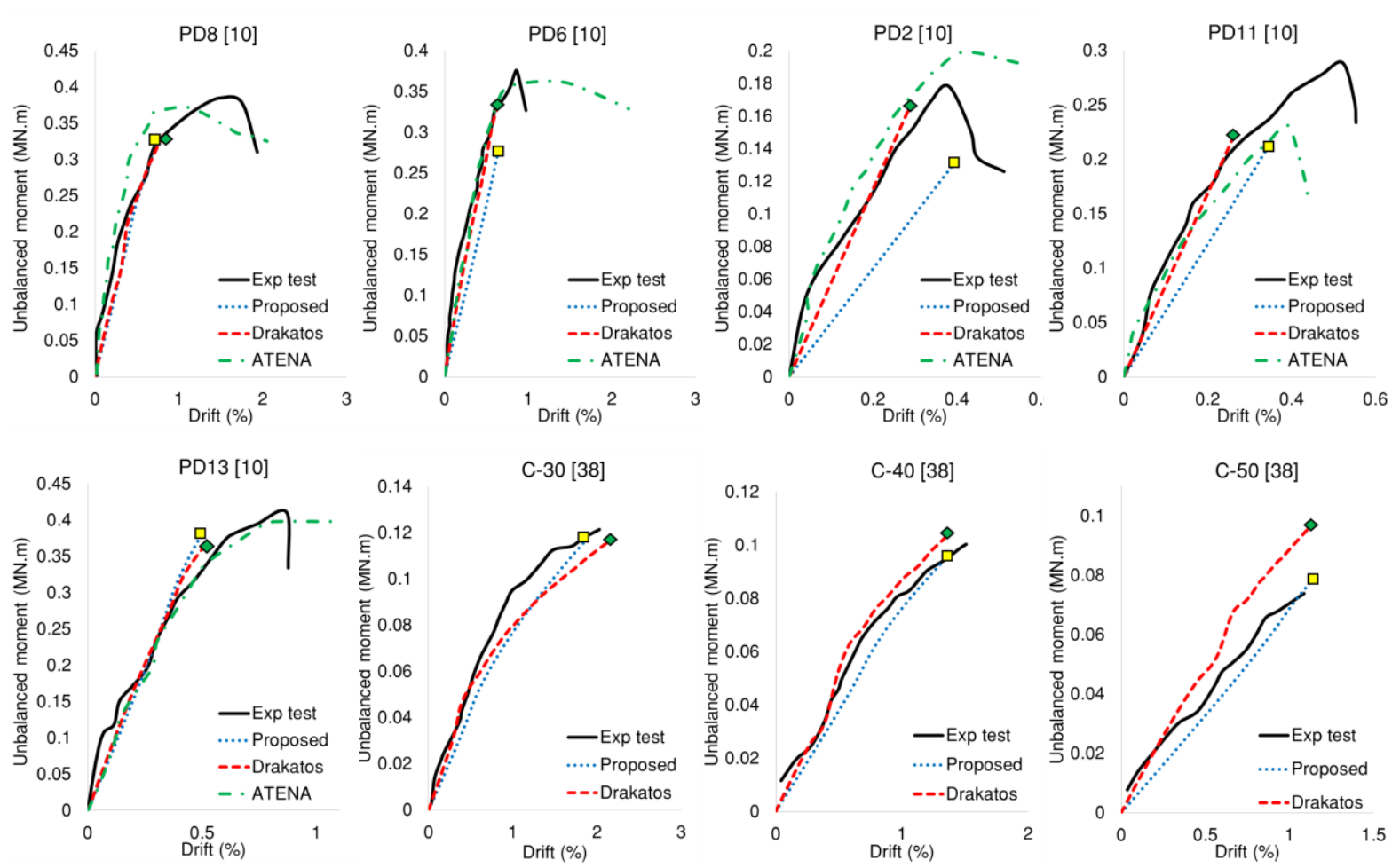

(a)
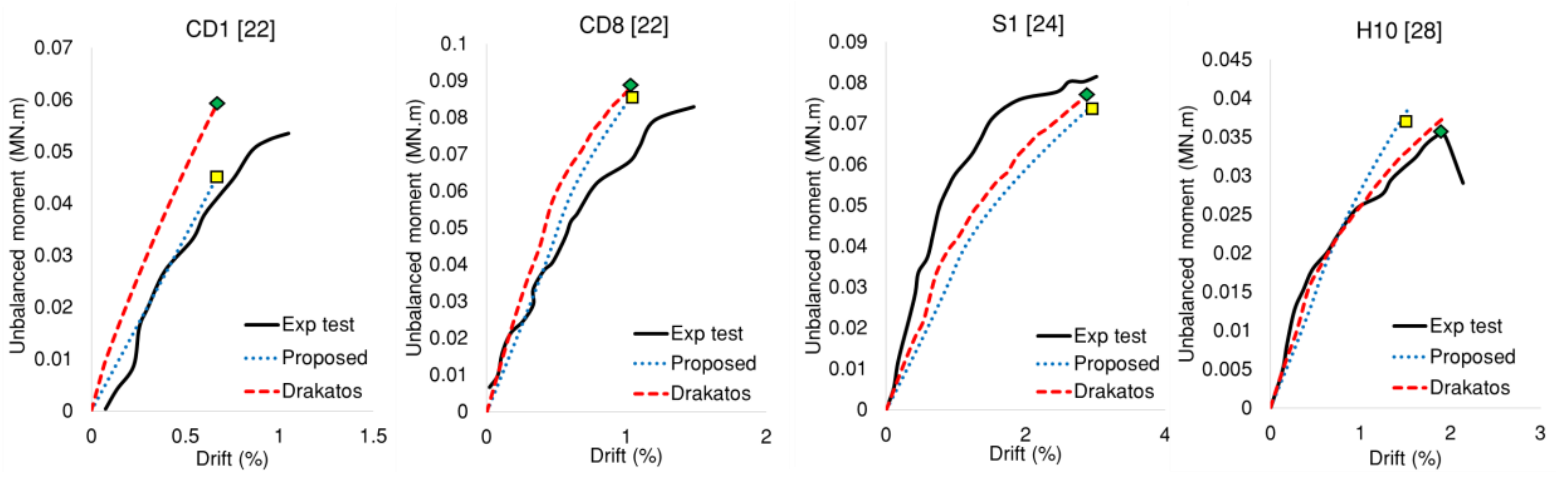

(b)
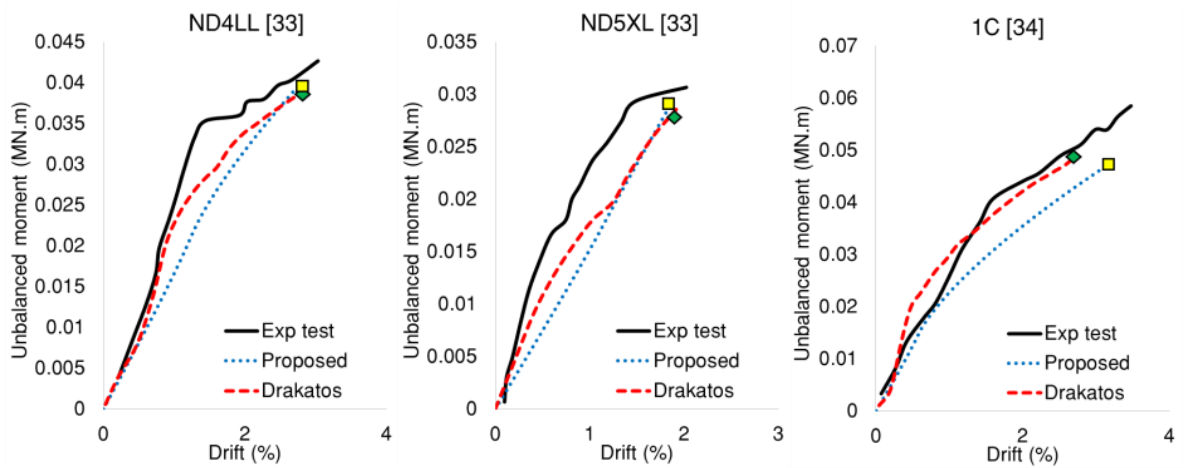

$\checkmark C S C T_{(c y c)}$ according to Drakatos et al. [7]

Failure criteria

according to

Equation 18 for proposed method

(c)

Figure 14. Comparison between experimental and predicted moment - rotation curve and failure point according to the proposed method and Drakatos et al. for: (a) test setup of Figure 1(a); (b) gravity load applied to the column; (c) gravity load applied to the slab (considering the additional contribution of slab outside $0.22 \mathrm{~L}$ ) 
Figure 15 shows the influence of GSR on the ratio of measured to predicted peak unbalanced moment for all 50 slabs in the database. As well as the proposed method, predictions are given for the methods of ACI 318-14 [3], Drakatos et al. [7], EC2 [44] and the CSCT [9] with $k_{e}$ from MC2010. All these design methods define the ultimate drift as that at peak unbalanced moment. Since drift is plotted at peak unbalanced moment the experimental drifts are unaffected by the presence or otherwise of integrity reinforcement which is required for robustness as described in ACI 318-14 [3]. Strength reduction and material safety factors for design codes are set to 1.0 and the aggregate size $d_{g}$ was taken as the reported size regardless of the use of either high strength or light weight concrete. Figure 15 shows that the average measured/predicted unbalanced moment is greater than 1.0 for all the methods with ACI 318 most conservative. The proposed method (Figure 15(a): $\sigma=1.141 ; C O V=0.213$ ) is comparable in accuracy to the much more complex method of Drakatos et al. [7] (Figure 15(b): $\sigma=1.150$; COV = 0.263). Lastly, comparison of the predictions obtained with the CSCT method using i) $k_{e}$ from MC2010 (Figure 15(e): $\sigma=1.257$; $C O V=0.274)$ and ii) $k_{e_{\text {mod }}}($ Figure 15(a)) shows that the proposed approach is most accurate.

The most critical test of the proposed method is its ability to predict the limiting rotation $\psi_{\text {scc peak }}$ at peak moment. Once $\psi_{\text {scc peak }}$ is known the LFRS can be designed accordingly and if necessary shear reinforcement can be provided to avoid brittle punching failure. Measured/predicted drifts at peak moment are shown in Figure 16 for all the considered methods. The limiting drift according to the methods of Hueste and Wight [2], ACI 318-14 [3] and Megally and Ghali [5] are as expressed below:

$$
\begin{array}{ll}
\text { Drift }=-0.125 G S R+0.065 \text { for GSR } \leq 0.4(G S R \geq 0.2) & (19 a) \\
\text { Drift }=-0.0167 G S R+0.0217 \text { for GSR }>0.4 & (19 b) \text { Hueste and Wight [2] } \\
\text { Drift }=-0.05 G S R+0.035 \geq 0.005(G S R \geq 0.1) & \text { (20) } \text { ACI } 318-14[3] \\
\text { Drift }=\frac{0.005}{\sqrt[0.85]{G S R}} & \text { (21) } \quad \text { Megally and Ghali }[5]
\end{array}
$$

The calculated drift limit was estimated as $\psi_{s c c} 0.85$ in the CSCT based methods (see Figures 16(a), (b) and (d)) for slabs with test setup C2. Figure 16 shows that the proposed method $(\sigma=1.250 ; C O V=$ 0.248), the CSCT with $k_{e}$ from MC2010 ( $\left.\sigma=1.404 ; C O V=0.257\right)$, and Drakatos et al. [7] $(\sigma=1.192$; $C O V=0.258$ ), have lower COV than the empirical methods. ACI 318-14, as intended, provides a lowerbound, rather than mean, estimate of drift capacity. The main benefits of the proposed method are its i) mechanical basis, ii) accuracy, and iii) simplicity compared with the comparably accurate method of Drakatos et al. [7]. 


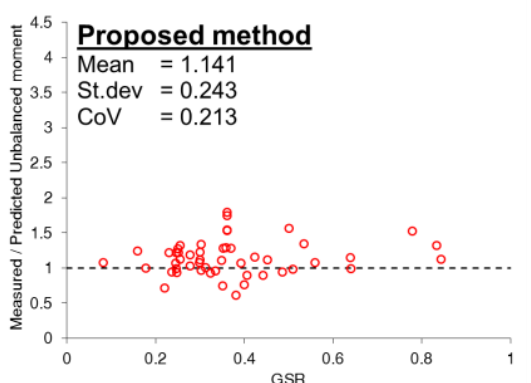

(a)

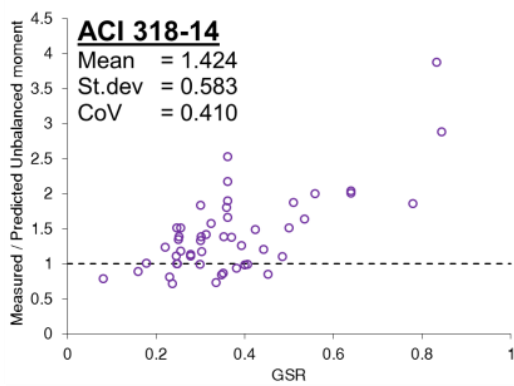

(c)

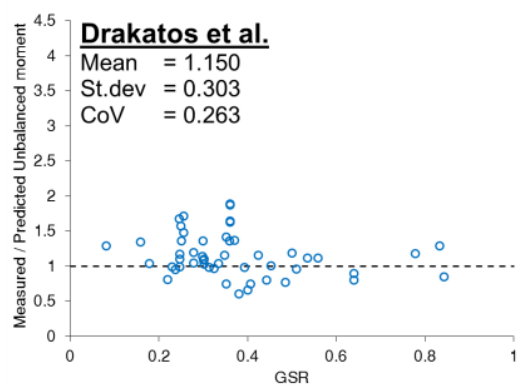

(b)

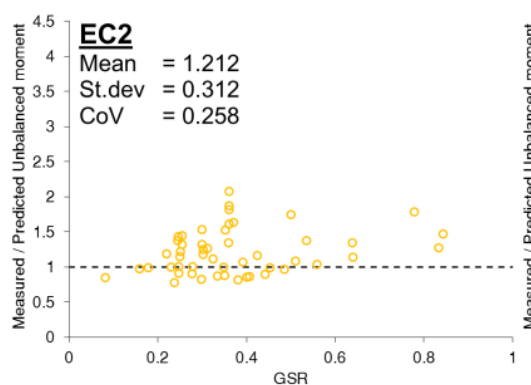

(d)

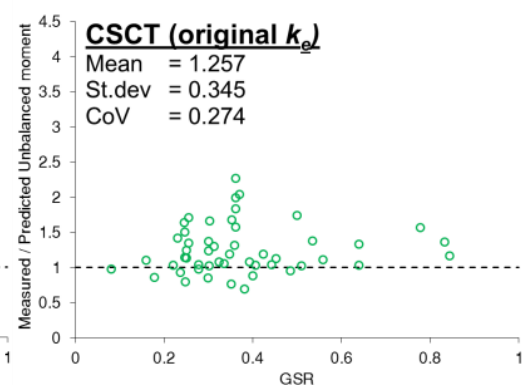

(e)

Figure 15. Measured to predicted unbalanced moment at failure according to: (a) proposed method; (b) Drakatos et al. [7]; (c) ACI 318-14 [3]; (d) EC2 [44]; (e) CSCT with original $k_{e}$ formulation $[9,21]$

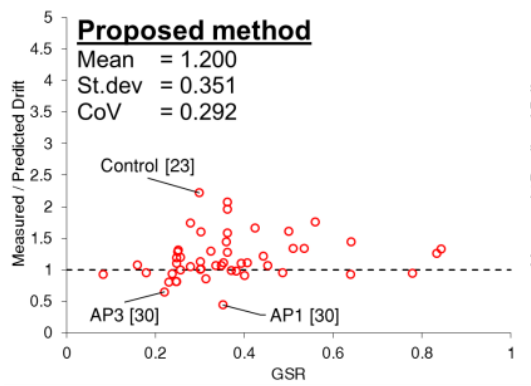

(a)

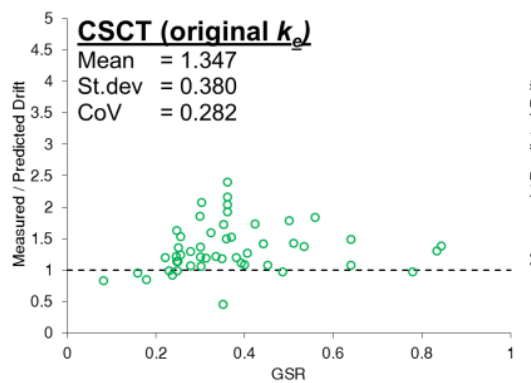

(d)

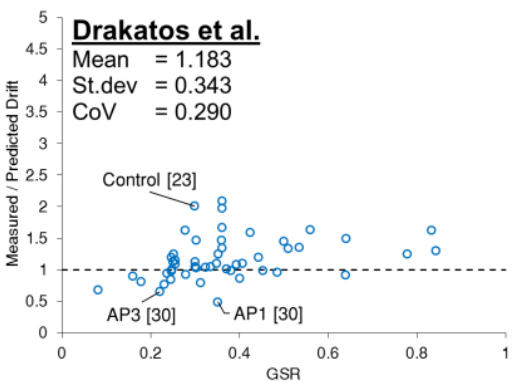

(b)

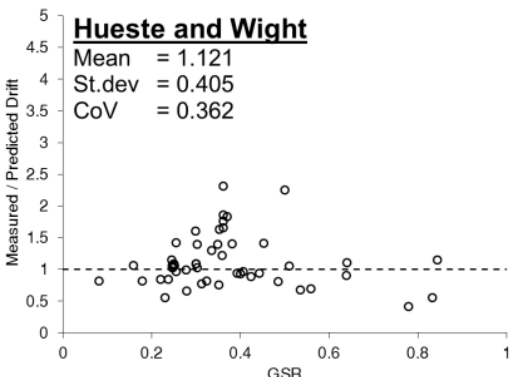

(e)

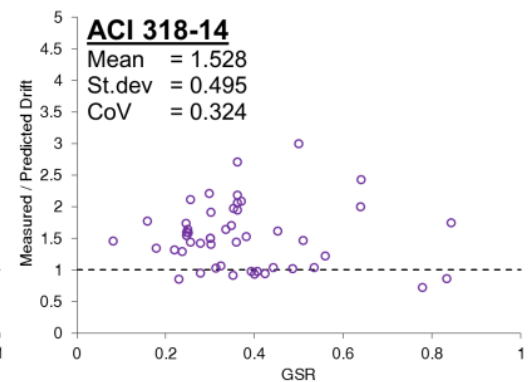

(c)

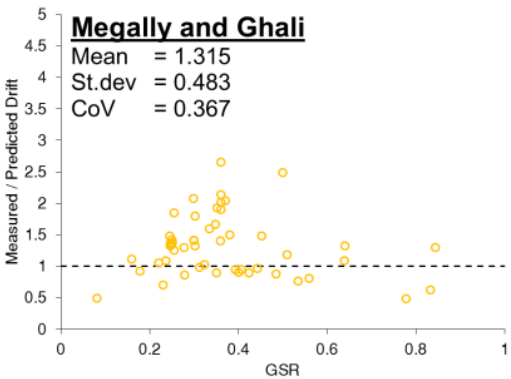

(f)

Figure 16. Measured to predicted drift at failure according to: (a) proposed method; (b) Drakatos et al. [7]; (c) ACI 318-14 [3]; (d) CSCT with original $k_{e}$ formulation [9, 21]; (e) Hueste and Wight [2]; (f) Megally and Ghali [5] 
Consideration of Figures 13, 16(a) and 16(b) shows that both the proposed approach and Drakatos et al. [7] significantly overestimate drift for specimens AP1 and AP3 of Pan and Moehle [30]. The reason for this is unknown. The drift predictions for AP1 and AP3 improve significantly if the maximum aggregate size is taken as $10 \mathrm{~mm}$ as used by Drakatos et al. [7] rather than $25.4 \mathrm{~mm}$ as stated in the original test report UCB/EERC-88/16 [45]. For an assumed aggregate size of $10 \mathrm{~mm}$, the proposed method gives ratios of experimental to predicted drift of 0.83 and 1.09 for specimens AP1 and AP3 respectively. It is also notable that all the proposed method gives a very conservative drift estimate for the "Control" specimen of Cho [23]. The reason for this is unknown but all the design methods give conservative drift predictions for this specimen (see Table A3). These three specimens are included in the statistics shown in Figure 16 even though they are possibly outliers.

Both the proposed method and that of Drakatos et al. [7] have several limitations. First, both approaches are derived for flat slabs that can be idealised as having axis-symmetric geometry and reinforcement arrangement. This is realistic for the common case where flat slabs are supported on square or circular columns that are equally spaced in each orthogonal direction. Second, neither model considers bidirectional loading on which only very limited test data are available.

\section{Code-like curve: GSR vs lateral drift limit}

A code-like curve relating GSR to lateral drift was produced using the proposed method for slabs with effective depths $(d)$ of $120 \mathrm{~mm}$ and $240 \mathrm{~mm}$ with hogging flexural reinforcement ratios $\left(\rho_{\text {hog }}\right)$ of $0.75 \%$ and $1.50 \%$. The following parameters were used for all slabs: square column with side length of $2 d ; f_{c}$ ' $=30 \mathrm{MPa}, f_{y}=460 \mathrm{MPa}, d_{g}=16 \mathrm{~mm}$ and slab span, $L=35 d$. In all cases, the sagging reinforcement ratio was taken as half of the hogging reinforcement ratio $\left(\rho_{\text {sag }}=0.5 \rho_{\text {hog }}\right)$ as adopted by Drakatos [37]. The practical GSR range was chosen to represent flat slabs without shear reinforcement designed to ACI 318-14 with gravity load equal to full dead load plus 25\% live load. Predictions from other analytical methods [6,7] and other empirically-based models [2, 3, 5] are also shown in Figure 15. To ensure a consistent comparison with the drift limits of the empirical models, drift calculated with all analytical methods was estimated as $\psi_{s c c} / 0.85$ to account for the contribution of the slab outside $r_{s}=0.22 \mathrm{~L}$. Figures 17(c) and (d) also include measured failure drifts and ATENA predictions for relevant specimens of Drakatos et al. [10] (see Table 1).

The analytical design methods in Figure 17(a) typically give slightly greater limiting drifts than the empirical design methods for slabs with $d=120 \mathrm{~mm}$ and $\rho_{\text {hog }}=0.75 \%$. The situation is reversed in Figure 17(b) for slabs with the same effective depth but $\rho_{\text {hog }}=1.5 \%$ since the analytical models predict shear stress to increase with $\rho_{\text {hog }}$ at any given drift. However, overall agreement is reasonable between the analytical and empirical methods in Figures 17(a) and (b). This is unsurprising since the considered slabs are representative of those in the databases used to calibrate the empirical models. Figures 17(c) and 17(d) show that for slabs with $d=240 \mathrm{~mm}$, all the considered analytical methods predict lower 
ultimate drifts than the empirical models. This is explained by the "size effect" phenomenon whereby slabs with larger effective depths experience larger crack width openings for the same drift causing failure to occur at lower drift (more brittle). The ATENA predictions in Figures 17(c) and 17(d) for slabs PD6, PD8 and PD13 are also consistent with the CSCT based predictions. The analytical and NLFEA results suggest that "extrapolating" the empirical methods beyond the test data used in their calibration may lead to unsafe results. However, it should be noted that ACI 318-14 gives reasonable drift predictions for the relatively thick $(250 \mathrm{~mm})$ slabs of Drakatos et al. [10] with GSR in the practical range for slabs without shear reinforcement. This arises since ACI 318-14 provides a lower bound to the test data on which it is based. Consequently, the level of accuracy of ACI 318-14 is very variable as shown in Figure 16(c). Adopting a mechanically based model leads to more consistent, and accurate, drift predictions as shown in Figure 16. The proposed method has the advantage of predicting both peak moment and $\psi_{\text {scc peak }}$ with reasonable accuracy while being considerably simpler than the sector model of Drakatos et al. [7].

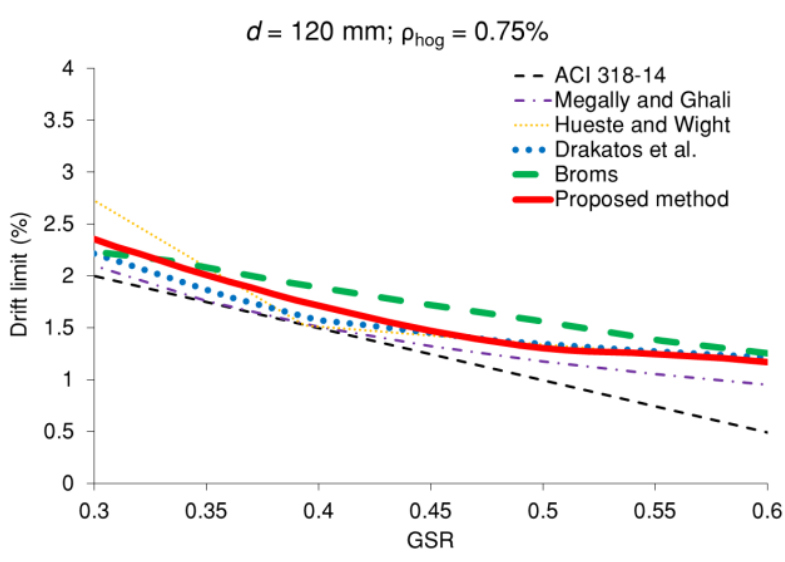

(a)

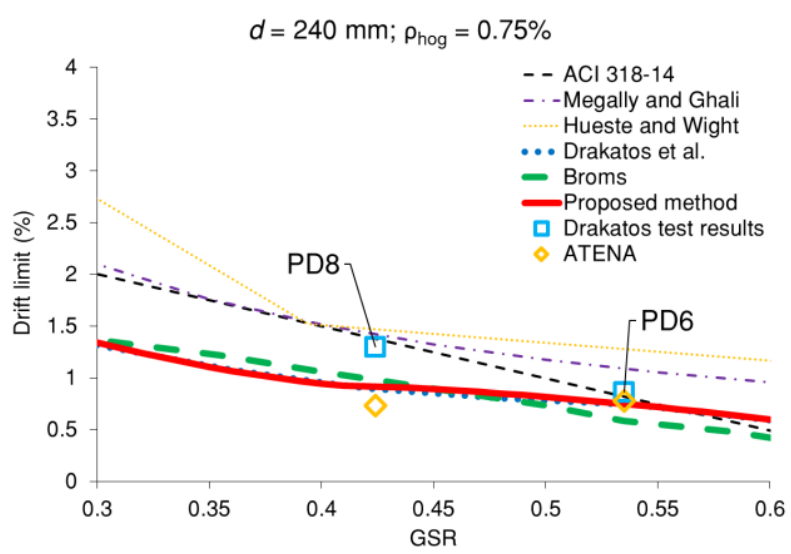

(c)

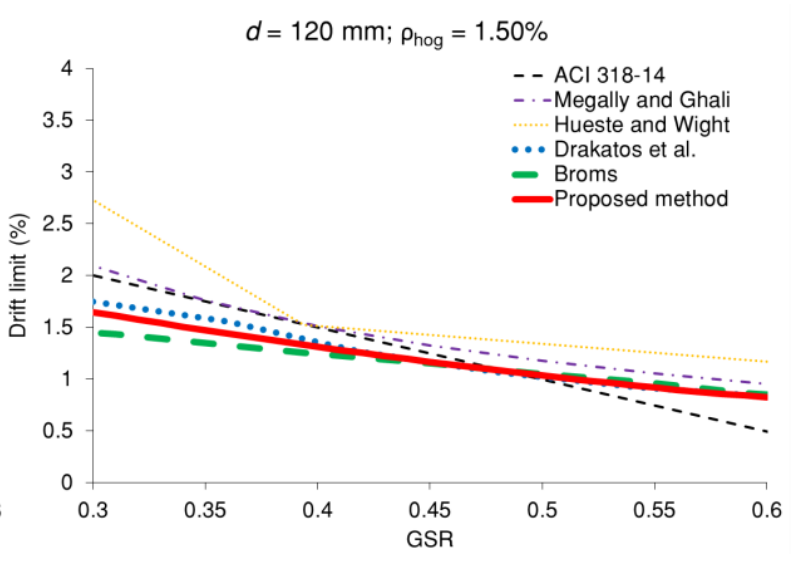

(b)

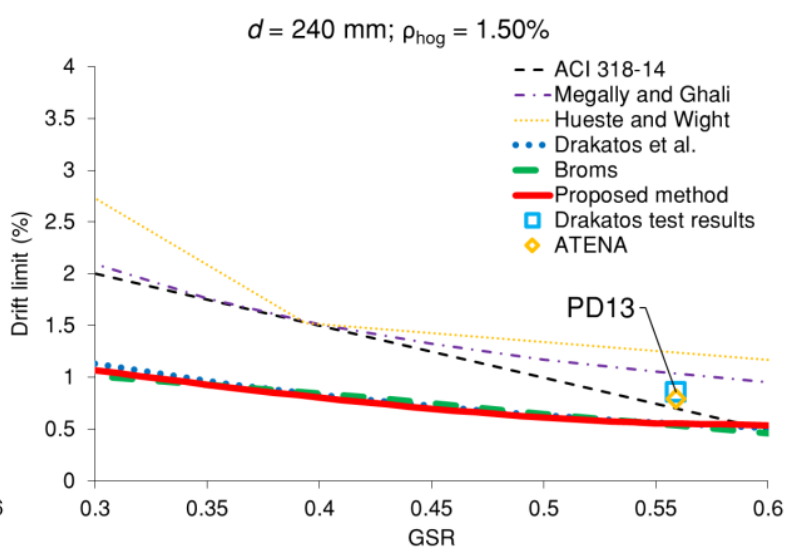

(d)

Figure 17. Code like curves produced by various approaches for slabs with: (a) $d=120 \mathrm{~mm}$, $\rho_{\text {hog }}=0.75 \%$; (b) $d=120 \mathrm{~mm}, \rho_{\text {hog }}=1.50 \%$; (c) $d=240 \mathrm{~mm}, \rho_{\text {hog }}=0.75 \%$; (d) $d=240 \mathrm{~mm}, \rho_{\text {hog }}=$ $1.50 \%$ 


\section{Conclusions}

This paper considers the assessment of internal slab-column connections without shear reinforcement subject to cyclic loading. Initially, behaviour is assessed using NLFEA with ATENA which is shown to be capable of broadly capturing the backbone response of internal slab-column connections subject to cyclic loading. Cyclic degradation and local behaviour such as sector-slab rotations, crack patterns, and flexural rebar strain were also reproduced accurately. As observed experimentally, cyclic degradation in the NLFEA is shown to be associated with accumulation of plastic strain in the flexural reinforcement close to the column [17]. Although a useful tool for investigating mechanisms of punching failure, NLFEA with solid elements is much too time consuming and complex for practical design and assessment. Consequently, an analytical method based on the CSCT was developed for predicting the peak unbalanced moment and corresponding drift. The basic control perimeter is reduced

by a multiple $k_{e_{\text {mod }}}$ to account for eccentric shear. The coefficient $k_{e_{m o d}}$ is related to $k_{e}$ in MC2010 but also accounts for slab slenderness and column size. In addition, a simple moment- $\psi_{s c c}$ relationship was developed based on a modification to LoA II in MC2010. The main simplification of the proposed method is that it separates the calculation of shear resistance and shear demand which negates the need to explicitly consider equilibrium of individual sector elements as done by Drakatos et al. [7]. The model was used to predict the peak moment and corresponding drift of 50 cyclically loaded internal slabcolumn connections without shear reinforcement. The proposed method is shown to produce safe results with less scatter than available empirically-based models. Comparisons of the proposed method with the related but much more complex model of Drakatos et al. [7] show that the accuracy of both methods is comparable. The simpler formulation of the proposed method makes it attractive as a practical design tool.

Code-like curves relating the GSR to the lateral drift limit were produced using the proposed analytical method for slabs with two different effective depths. The resulting design curves suggest that available empirical-models, including the seismic provisions of ACI 318-14 section 18.14.5.1, may be unsafe for slabs with large effective depths or large hogging reinforcement ratios. This is in agreement with previous findings $[6,7]$ and has concerning implications for the safety of seismically loaded flat slabs designed to ACI 318-14. Further experimental studies are required to confirm the prediction of the analytical model.

\section{Acknowledgement}

The work presented in this article was supported by the Indonesia Endowment Fund for Education (LPDP). The opinions and conclusions in this document are those of the authors, and do not necessarily represent those of the sponsors. 


\section{References}

[1] Ghali, A., and Megally, S., 2000. Stud Shear Reinforcement for Punching: North American and European Practices, Proceedings of the International Workshop on Punching Shear Capacity of RC Slabs, Kungl Tekniska Hogskolan Institute for Byggkonstruktion, Stockholm, Sweden, pp. 201-209.

[2] Hueste, M. and J. Wight, 1999. Nonlinear Punching Shear Failure Model for Interior Slab-Column Connections. Journal of Structural Engineering 125(9): 997-1008.

[3] ACI Committee 318, 2014. ACI Building Code Requirements for Structural Concrete (ACI 318-14) and Commentary (ACI 318R-14). American Concrete Institute, Farmington Hills, MI, 519 pp.

[4] BSI, 2004. BS EN 1998-1:2004+A1:2013: Eurocode 8, Design of Structures for Earthquake Resistance - Part 1: General rules, seismic actions and rules for buildings. BSI, London, UK.

[5] Megally, S. \& Ghali, A., 1994. Design considerations for slab-column connections in seismic zones. ACI Structural Journal, 91(3), pp.303-314.

[6] Broms C. E., 2009. Design method for imposed rotations of interior slab-column connections. ACI Structural Journal, Vol. 106, No. 5, pp. 636-645, Farmington Hills, U.S.A.

[7] Drakatos, I.S., Muttoni, A. \& Beyer, K., 2018. Mechanical Model for Drift-Induced Punching of SlabColumn Connections without Transverse Reinforcement. ACI Structural Journal, 115(2).

[8] Cervenka, V., Jendele, L., and Cervenka, J., 2007. ATENA Program Documentation, Part 1, Theory. Cervenka Consulting, Prague, 231.

[9] Muttoni, A., 2008. Punching Shear Strength of Reinforced Concrete Slabs without Transverse Reinforcement, ACI Structural Journal, V. 105, No. 4, pp. 440-450.

[10] Drakatos, I.S., Muttoni, A. \& Beyer, K., 2016. Internal slab-column connections under monotonic and cyclic imposed rotations. Engineering Structures, 123, pp.501-516.

[11] Tian, Y., Jirsa, J.O., Bayrak, O., Widianto \& Argudo, J.F., 2008, Behavior of Slab-Column Connections of Existing Flat-Plate Structures. ACI Structural Journal 105(5).

[12] Bazant, Z. \& Oh, B., 1983. Crack band theory of concrete. Materials and Structures, 16, pp.155-177.

[13] Menetrey, P. \& Willam, K.J., 1995. Triaxial failure criterion for concrete and its generalization. ACI Structural Journal, 92(3), pp.311-318.

[14] Vecchio, F. J. \& Collins, M. P., 1986. The modified-compression field theory for reinforced concrete elements subjected to shear. ACI Structural Journal, V. 83, No. 2, pp. 219-231.

[15] Guandalini, S., Burdet, O.L. \& Muttoni, A., 2009. Punching tests of slabs with low reinforcement ratios. ACI Structural Journal, 106(1), pp.87-95.

[16] Sagaseta, J., Muttoni, A., Ruiz, M. F. \& Tassinari, L., 2011. Non-axis-symmetrical punching shear around internal columns of RC slabs without transverse reinforcement. Magazine of Concrete Research, 63(6), pp.441-457.

[17] Setiawan, A., Vollum, R. \& Macorini, L., 2018. Nonlinear Finite Element Analysis of Reinforced Concrete Flat Slabs Subjected to Reversed-Cyclic Loading. In D. A. Hordijk \& M. Luković, eds. High Tech Concrete: Where Technology and Engineering Meet: Proceedings of the 2017 fib Symposium, held in Maastricht, The Netherlands, June 12-14, 2017. Cham: Springer International Publishing, pp. 814-822.

[18] Menegotto, M., and Pinto, P., 1973. Method of analysis for cyclically loaded reinforced concrete plane frames including changes in geometry and non-elastic behavior of elements under combined normal force and bending. Proc., IABSE Symposium on Resistance and Ultimate Deformability of Structures Acted on by Well-Defined Repeated Loads, Final Report, Lisbon.

[19] CEB-FIP MC90, 1993, Design of Concrete Structures-CEB-FIP-Model Code 1990, Thomas Telford, London, UK, $437 \mathrm{pp}$.

[20] Kinnunen, S. \& Nylander, H., 1960, Punching of Concrete Slabs without Shear Reinforcement, Transactions of the Royal Institute of Technology, No. 158, Sweden, $112 \mathrm{pp}$.

[21] fib (Fédération International du Béton), 2013. fib Model Code for concrete structures 2010. Fédération International du Béton, Lausanne, Switzerland.

[22] Cao H., 1993. Seismic design of slab-column connections, M.Sc. Thesis, University of Calgary, 201 p., Calgary, Canada.

[23] Cho Y. S., 2009. Structural performance of RC flat plate slab shear-reinforced interior connections under lateral loading. Magazine of Concrete Research, Vol. 61, No. 3, pp. 155-164, London, United Kingdom. 
[24] Choi J. -W., Ali M., Alexander S. D. B., 2009. Behavior of slab-column connections with partially debonded reinforcement under lateral loading. Canadian Journal of Civil Engineering, Vol. 36, No. 3, pp. 463-472, Ottawa, Canada.

[25] Choi M. -S., Cho I. -J., Han B. -S., Ahn J. -M., Shin S. -W., 2007. Experimental study of interior slabcolumn connections subjected to vertical shear and cyclic moment transfer. Key Engineering Materials, Vols. 348-349, pp. 641-644, Switzerland.

[26] Islam S., Park R., 1976. Tests on slab-column connections with shear and unbalanced flexure, Journal of the Structural Division, Proceedings of ASCE, Vol. 102, No. ST3, pp. 549-568, U.S.A.

[27] Kang T. H. -K., Wallace J. W., 2008. Seismic performance of reinforced concrete slab- column connections with thin plate stirrups. ACI Structural Journal, Vol. 105, No. 5, pp. 617-625, Farmington Hills, U.S.A.

[28] Kanoh, Y. \& Yoshizaki, S., 1975. Experiments on slab-column and slab-wall connections of flat plate structures, Concrete Journal, Japan Concrete Institute, Vol. 13, pp. 7-19, Tokyo, Japan.

[29] Morrison D. G., Hirasawa I., Sozen M. A., 1983. Lateral-load tests of R/C slab-column connections, Journal of Structural Engineering, ASCE, Vol. 109, No. 11, pp. 2698-2714, Reston, U.S.A.

[30] Pan A. A., Moehle J. P., 1989. Lateral displacement ductility of reinforced concrete flat plates, ACI Structural Journal, Vol. 86, No. 3, pp. 250-258, Detroit, U.S.A.

[31] Park H. -G., Kim Y. -N., Song J. -G., Kang S. -M., 2012. Lattice shear reinforcement for enhancement of slab-column connections, Journal of Structural Engineering, ASCE, Vol. 138, No. 3, pp. 425-437, Reston, U.S.A.

[32] Park Y. -M., Han S. -W., Ryu J. -H., 2007. Comparison of seismic behaviors of interior joints on PT and RC flat plate systems. Key Engineering Materials, Vols. 348-349, pp. 741-745, Switzerland.

[33] Robertson I. N., Johnson G., 2006. Cyclic lateral loading of non-ductile slab-column connections. ACI Structural Journal, Vol. 103, No. 3, pp. 356-364, Farmington Hills, U.S.A.

[34] Robertson I. N., Kawai T., Lee J., Enomoto B., 2002. Cyclic testing of slab-column connections with shear reinforcement. ACI Structural Journal, Vol. 99, No. 5, pp. 605- 613, Farmington Hills, U.S.A.

[35] Stark A., Binici B., Bayrak O., 2005. Seismic upgrade of reinforced concrete slab-column connections using carbon fiber-reinforced polymers. ACI Structural Journal, Vol. 102, No. 2, pp. 324-333, Farmington Hills, U.S.A.

[36] Zee H. L., Moehle J. P., 1984. Behavior of interior and exterior flat plate connections subjected to inelastic load reversals, Report No. UCB/EERC 84/07, Earthquake Engineering Research Center, College of Engineering, University of California, pp. 1-145, Berkeley, California, U.S.A.

[37] Drakatos, I. S., 2016. Seismic behaviour of slab-column connections without transverse reinforcement, EPFL.

[38] Almeida, A.F.O., Inacio, M.M.G., Lucio, V.J.G., Ramos, A.P., 2016. Punching behaviour of RC flat slabs under reversed horizontal cyclic loading. Engineering Structures, 117, pp.204-219.

[39] Emam, M., Marzouk, H. \& Hilal, M.S., 1997. Seismic Response of Slab-Column Connections Constructed with High-Strength Concrete. ACI Structural Journal, pp.197-204.

[40] Marzouk, H., Osman, M. \& Hussein, A., 2001. Cyclic Loading of High-Strength Lightweight Concrete Slabs. ACI Structural Journal, (98), pp.207-214.

[41] Robertson, I. N., 1990. Seismic Response of Connections in Indeterminate Flat-Slab Subassemblies, $\mathrm{PhD}$ thesis, Rice University, Houston, TX, $258 \mathrm{pp}$.

[42] Song, J., Kim, J., Song, H., Song, J., 2012. Effective Punching Shear and Moment Capacity of Flat Plate- Column Connection with Shear Reinforcements for Lateral Loading. International Journal of Concrete Structures and Materials, 6(1), pp.19-29.

[43] Wey E. H., Durrani A. J., 1992. Seismic response of interior slab-column connections with shear capitals. ACI Structural Journal, Vol. 89, No. 6, pp. 682-691, Detroit, U.S.A.

[44] BSI, 2004. BS EN 1992-1-1:2004: Eurocode 2, design of concrete structures - part 1-1: general rules and rules for buildings. BSI, London, UK.

[45] Pan A. A., Moehle J. P., 1988. Reinforced Concrete Flat Plates Under Lateral Loading: an Experimental Study including Biaxial Effects. Report No. UCB/EERC-88/16, Earthquake Engineering Research Center, College of Engineering, University of California, pp. 1-285, Berkeley, California, U.S.A. 
APPENDIX A

Table A1. Details of slab geometry and material properties for cyclic assessment

\begin{tabular}{|c|c|c|c|c|c|c|c|c|c|c|c|c|c|c|c|c|}
\hline \multirow[b]{2}{*}{ No } & \multirow[b]{2}{*}{ Source } & \multirow[b]{2}{*}{ Specimen } & \multirow[b]{2}{*}{$\begin{array}{c}\text { Gravity } \\
\text { load } \\
\text { applied to }\end{array}$} & \multirow[b]{2}{*}{$\begin{array}{c}\text { GSR } \\
(\mathrm{ACI} \\
\text { 318-14) }\end{array}$} & \multicolumn{10}{|c|}{ Specimen geometry and loading parameter } & \multirow{2}{*}{$\begin{array}{c}\text { Drift or } \\
\psi_{\text {scc }}(\%) \\
\text { if } \\
\text { known }\end{array}$} & \multirow[b]{2}{*}{$\begin{array}{c}\text { Unbalance } \\
\text { d moment } \\
\text { (kN.m) }\end{array}$} \\
\hline & & & & & $\begin{array}{c}c \\
(\mathbf{m m})\end{array}$ & $\begin{array}{c}h \\
(\mathbf{m m})\end{array}$ & $\begin{array}{c}d \\
(\mathrm{~mm})\end{array}$ & $\begin{array}{r}\text { Slab } \\
\text { width } \\
(\mathrm{mm})\end{array}$ & $r_{s}(\mathbf{m m})$ & $\begin{array}{c}f_{c^{\prime}} \\
(\mathbf{M P a} \\
)\end{array}$ & $\begin{array}{c}d_{g} \\
(\mathrm{~mm})\end{array}$ & $\begin{array}{c}f_{y} \\
(\mathbf{M P a} \\
)\end{array}$ & $\begin{array}{l}\rho_{t o p} \\
(\%)\end{array}$ & $\begin{array}{l}\rho b o t \\
(\%)\end{array}$ & & \\
\hline 1 & \multirow{5}{*}[10]{} & PD2 & \multirow{5}{*}{ Other $\dagger$} & 0.778 & 390 & 250 & 198.0 & 3000 & 1500.0 & 36.9 & 16 & 558 & $1.13 *$ & $0.66 *$ & 0.36 & 196.00 \\
\hline 2 & & PD6 & & 0.535 & 390 & 250 & 199.0 & 3000 & 1500.0 & 38.3 & 16 & 507 & $1.16^{*}$ & $0.65 *$ & 0.86 & 372.00 \\
\hline 3 & & PD8 & & 0.424 & 390 & 250 & 198.0 & 3000 & 1500.0 & 32.7 & 16 & 575 & $1.12 *$ & $0.60 *$ & 1.30 & 384.00 \\
\hline 4 & & PD11 & & 0.833 & 390 & 250 & 196.0 & 3000 & 1500.0 & 33.1 & 16 & 593 & $1.91 *$ & $1.02 *$ & 0.43 & 286.00 \\
\hline 5 & & PD13 & & 0.559 & 390 & 250 & 196.0 & 3000 & 1500.0 & 36.5 & 16 & 546 & $1.94 *$ & $1.05 *$ & 0.86 & 410.00 \\
\hline 6 & [11] & L0.5 & Column & 0.230 & 406 & 152 & 127.0 & 3657 & 1828.5 & 25.6 & 10 & 469 & 0.50 & 0.30 & 2.00 & 128.00 \\
\hline 7 & \multirow{3}{*}{ [22] } & CD1 & \multirow{3}{*}{ Column } & 0.843 & 250 & 150 & 115.0 & 1900 & 950.0 & 40.4 & 20 & 395 & 1.34 & 0.45 & 0.87 & 50.00 \\
\hline 8 & & CD5 & & 0.640 & 250 & 150 & 115.0 & 1900 & 950.0 & 31.2 & 20 & 395 & 1.34 & 0.45 & 1.22 & 70.50 \\
\hline 9 & & CD8 & & 0.510 & 250 & 150 & 116.0 & 1900 & 950.0 & 27.0 & 20 & 395 & 1.34 & 0.45 & 1.39 & 84.60 \\
\hline 10 & [23] & Control & $\begin{array}{c}\text { Column + } \\
\text { slab** }\end{array}$ & 0.299 & 300 & 150 & 130.0 & 2800 & 616.0 & 34.3 & 25 & 392 & 0.90 & 0.25 & 4.44 & 111.57 \\
\hline 11 & [24] & SPB & Slab & 0.250 & 355 & 152 & 106.0 & 4200 & 924.0 & 34.1 & 16 & 440 & 1.40 & 0.25 & 3.69 & 150.00 \\
\hline 12 & \multirow{3}{*}{ [25] } & S1 & \multirow{3}{*}{ Column } & 0.300 & 300 & 120 & 90.0 & 2400 & 1200.0 & 33.5 & 16 & 458 & 1.00 & 0.50 & 3.00 & 83.10 \\
\hline 13 & & S2 & & 0.500 & 300 & 120 & 90.0 & 2400 & 1200.0 & 41.3 & 16 & 458 & 1.00 & 0.50 & 3.00 & 74.80 \\
\hline 14 & & S3 & & 0.300 & 300 & 120 & 90.0 & 2400 & 1200.0 & 37.8 & 16 & 458 & 1.50 & 0.75 & 3.00 & 121.50 \\
\hline 15 & [26] & IP3C & Column & 0.246 & 200 & 89 & 70.0 & 2240 & 1120.0 & 29.7 & 6 & 316 & 0.83 & 0.43 & 3.62 & 35.80 \\
\hline 16 & [27] & $\mathrm{CO}$ & Column & 0.302 & 254 & 150 & 130.0 & 2896 & 1447.8 & 38.6 & 10 & 452 & 0.52 & 0.20 & 2.80 & 111.56 \\
\hline 17 & \multirow{3}{*}{ [28] } & H9 & \multirow{3}{*}{ Column } & 0.313 & 200 & 100 & 80.0 & 1800 & 900.0 & 22.8 & 10 & 361 & 0.70 & 0.70 & 2.00 & 33.00 \\
\hline 18 & & H10 & & 0.324 & 200 & 100 & 80.0 & 1800 & 900.0 & 22.8 & 10 & 361 & 1.12 & 1.12 & 2.00 & 36.10 \\
\hline 19 & & H11 & & 0.639 & 200 & 100 & 80.0 & 1800 & 900.0 & 23.2 & 10 & 361 & 1.12 & 1.12 & 1.00 & 25.20 \\
\hline
\end{tabular}




\begin{tabular}{|c|c|c|c|c|c|c|c|c|c|c|c|c|c|c|c|c|}
\hline 20 & \multirow{2}{*}{ [29] } & $\mathrm{S} 4$ & \multirow{2}{*}{ Slab } & 0.081 & 305 & 76 & 61.0 & 1829 & 402.4 & 34.9 & 10 & 320 & 0.98 & 0.98 & 4.50 & 35.50 \\
\hline 21 & & S5 & & 0.159 & 305 & 76 & 62.0 & 1829 & 402.4 & 35.2 & 10 & 340 & 0.98 & 0.98 & 4.80 & 37.50 \\
\hline 22 & \multirow[t]{2}{*}{ [30] } & AP1 & $\begin{array}{c}\text { Column + } \\
\text { slab** }\end{array}$ & 0.351 & 274 & 122 & 101.0 & 3660 & 805.2 & 33.3 & 25 & 472 & 0.76 & 0.25 & 1.60 & 52.06 \\
\hline 23 & & AP3 & Column & 0.220 & 274 & 122 & 101.0 & 3660 & 1830.0 & 31.4 & 25 & 472 & 0.76 & 0.25 & 3.17 & 86.77 \\
\hline 24 & \multirow{2}{*}{ [31] } & $\mathrm{RCA}$ & \multirow{2}{*}{ Column } & 0.442 & 300 & 135 & 114.0 & 2700 & 1350.0 & 22.5 & 10 & 430 & 1.06 & 0.79 & 1.34 & 70.70 \\
\hline 25 & & $\mathrm{RCB}$ & & 0.406 & 300 & 135 & 114.0 & 2700 & 1350.0 & 38.7 & 10 & 430 & 1.06 & 0.79 & 1.44 & 81.25 \\
\hline 26 & [32] & RI-50 & $\begin{array}{c}\text { Column + } \\
\text { slab** }\end{array}$ & 0.370 & 300 & 132 & 102.0 & 3400 & 1700.0 & 32.3 & 16 & 392 & 0.64 & 0.27 & 3.44 & 91.64 \\
\hline 27 & \multirow{5}{*}{ [33] } & ND1C & \multirow{5}{*}{ Slab } & 0.237 & 254 & 114 & 100.0 & 2743 & 603.5 & 29.6 & 10 & 441 & 0.53 & 0.36 & 3.00 & 42.39 \\
\hline 28 & & ND4LL & & 0.348 & 254 & 114 & 100.0 & 2743 & 603.5 & 32.3 & 10 & 441 & 0.53 & 0.36 & 3.00 & 44.45 \\
\hline 29 & & ND5XL & & 0.452 & 254 & 114 & 100.0 & 2743 & 603.5 & 24.1 & 10 & 441 & 0.53 & 0.36 & 2.00 & 32.52 \\
\hline 30 & & ND6HR & & 0.278 & 254 & 114 & 100.0 & 2743 & 603.5 & 26.3 & 10 & 441 & 0.93 & 0.67 & 3.00 & 58.58 \\
\hline 31 & & ND7LR & & 0.335 & 254 & 114 & 100.0 & 2743 & 603.5 & 18.8 & 10 & 441 & 0.39 & 0.36 & 3.00 & 29.91 \\
\hline 32 & {$[34]$} & $1 \mathrm{C}$ & Slab & 0.247 & 250 & 115 & 96.0 & 2743 & 603.5 & 35.4 & 10 & 420 & 0.70 & 0.42 & 3.50 & 58.30 \\
\hline 33 & [35] & C-02 & Column & 0.381 & 305 & 115 & 82.3 & 2440 & 1220.0 & 30.9 & 19 & 454 & 1.42 & 0.51 & 2.44 & 44.61 \\
\hline 34 & [36] & INT & Slab & 0.302 & 137 & 61 & 51.5 & 1828 & 402.2 & 26.2 & 10 & 434 & 0.80 & 0.34 & 3.81 & 10.27 \\
\hline 35 & \multirow{3}{*}{ [38] } & C-30 & \multirow{3}{*}{ Other $\dagger$} & 0.278 & 250 & 150 & 118.0 & 4150 & 913.0 & 66.5 & 16 & 526 & 0.96 & 0.67 & 2.00 & 121.60 \\
\hline 36 & & C-40 & & 0.392 & 250 & 150 & 119.0 & 4150 & 913.0 & 53.1 & 16 & 526 & 0.96 & 0.67 & 1.50 & 102.80 \\
\hline 37 & & $\mathrm{C}-50$ & & 0.485 & 250 & 150 & 118.0 & 4150 & 913.0 & 52.4 & 16 & 526 & 0.96 & 0.67 & 1.10 & 74.80 \\
\hline 38 & \multirow{4}{*}{ [39] } & Н.H.H.C.0.5 & \multirow{4}{*}{ Column } & 0.245 & 250 & 150 & 119.0 & 1870 & 935.0 & 75.8 & 19 & 460 & 0.50 & 0.26 & 3.95 & 134.47 \\
\hline 39 & & H.H.H.C.1.0 & & 0.251 & 250 & 150 & 119.0 & 1870 & 935.0 & 72.3 & 19 & 460 & 1.00 & 0.26 & 3.56 & 162.97 \\
\hline 40 & & N.H.H.C.0.5 & & 0.352 & 250 & 150 & 119.0 & 1870 & 935.0 & 36.8 & 19 & 460 & 0.50 & 0.26 & 3.43 & 100.48 \\
\hline 41 & & N.H.H.C.1.0 & & 0.359 & 250 & 150 & 119.0 & 1870 & 935.0 & 35.4 & 19 & 460 & 1.00 & 0.26 & 2.45 & 127.24 \\
\hline 42 & \multirow{3}{*}[40]{} & HSLW0.5C & \multirow{3}{*}{ Column } & 0.255 & 250 & 150 & 119.0 & 1870 & 935.0 & 70.0 & 19 & 460 & 0.50 & 0.26 & 4.70 & 135.80 \\
\hline 43 & & HSLW1.0C & & 0.255 & 250 & 150 & 119.0 & 1870 & 935.0 & 70.0 & 19 & 460 & 1.00 & 0.26 & 3.20 & 174.00 \\
\hline 44 & & NSLW0.5C & & 0.361 & 250 & 150 & 119.0 & 1870 & 935.0 & 35.0 & 19 & 460 & 0.50 & 0.26 & 4.60 & 116.20 \\
\hline
\end{tabular}




\begin{tabular}{|c|c|c|c|c|c|c|c|c|c|c|c|c|c|c|c|c|}
\hline 45 & & NSLW1.0C & & 0.361 & 250 & 150 & 119.0 & 1870 & 935.0 & 35.0 & 19 & 460 & 1.00 & 0.26 & 3.30 & 151.70 \\
\hline 46 & & NSNW0.5C & & 0.361 & 250 & 150 & 119.0 & 1870 & 935.0 & 35.0 & 19 & 460 & 0.50 & 0.26 & 3.70 & 132.37 \\
\hline 47 & & NSNW1.0C & & 0.361 & 250 & 150 & 119.0 & 1870 & 935.0 & 35.0 & 19 & 460 & 1.00 & 0.26 & 3.50 & 176.40 \\
\hline 48 & [41] & $8 \mathrm{I}$ & Slab & 0.178 & 250 & 114 & 89.0 & 2896 & 637.0 & 39.3 & 25 & 525 & 0.83 & 0.36 & 3.50 & 60.15 \\
\hline 49 & [42] & $\mathrm{RC} 1$ & Column & 0.400 & 300 & 135 & 113.5 & 2700 & 1350.0 & 38.7 & 16 & 449 & 1.06 & 0.79 & 1.40 & 80.75 \\
\hline 50 & [43] & $\mathrm{SC0}$ & Slab & 0.247 & 250 & 114 & 96.8 & 2896 & 637.0 & 39.3 & 25 & 525 & 0.89 & 0.32 & 3.50 & 62.03 \\
\hline
\end{tabular}

Notes:

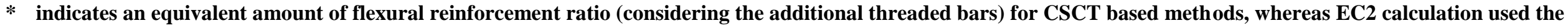
value of $\rho_{t o p}$ and $\rho_{b o t}$ as given in Table 1

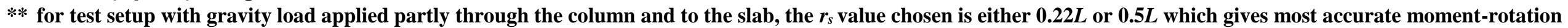
response compared to the measured data

$\dagger$ test setup with unusual boundary conditions:

a) Drakatos et al. : gravity load is applied through steel plate at $0.22 \mathrm{~L}$ and unbalanced moment is applied through steel arm at $0.5 \mathrm{~L}$

b) Almeida et al. : gravity load is applied through steel plate at $0.22 \mathrm{~L}$, unbalanced moment applied through the column while allowing equal rotation and vertical displacement at both slab edges (allowing the movement of the zero radial moment line) 
Table A2. Summary of measured to predicted unbalanced moment from slab database

\begin{tabular}{|c|c|c|c|c|c|c|c|c|c|}
\hline \multirow[b]{2}{*}{ No } & \multirow[b]{2}{*}{ Source } & \multirow[b]{2}{*}{ Specimen } & \multirow[b]{2}{*}{ GSR } & \multirow{2}{*}{$\begin{array}{c}\text { Measured } \\
\text { peak } \\
\text { unbalanced } \\
\text { moment } \\
\text { (kN.m) }\end{array}$} & \multicolumn{5}{|c|}{ Measured/Predicted Peak unbalanced moment } \\
\hline & & & & & ACI 318-14 & EC2 & $\begin{array}{c}\text { CSCT with } \\
\text { original } k_{e} \\
\text { formulation }\end{array}$ & $\begin{array}{c}\text { Proposed } \\
\text { method }\end{array}$ & $\begin{array}{l}\text { Drakatos et } \\
\text { al. method }\end{array}$ \\
\hline 1 & \multirow{5}{*}[10]{} & PD2 & 0.78 & 196.00 & 1.861 & 1.787 & 1.568 & 1.524 & 1.179 \\
\hline 2 & & PD6 & 0.53 & 372.00 & 1.637 & 1.375 & 1.380 & 1.342 & 1.116 \\
\hline 3 & & PD8 & 0.42 & 384.00 & 1.489 & 1.168 & 1.193 & 1.159 & 1.155 \\
\hline 4 & & PD11 & 0.83 & 286.00 & 3.874 & 1.277 & 1.365 & 1.321 & 1.287 \\
\hline 5 & & PD13 & 0.56 & 410.00 & 2.001 & 1.036 & 1.112 & 1.076 & 1.111 \\
\hline 6 & [11] & L0.5 & 0.23 & 128.00 & 0.808 & 0.998 & 1.418 & 1.222 & 0.989 \\
\hline 7 & \multirow{3}{*}{ [22] } & CD1 & 0.84 & 50.00 & 2.878 & 1.472 & 1.170 & 1.127 & 0.843 \\
\hline 8 & & CD5 & 0.64 & 70.50 & 2.008 & 1.137 & 1.032 & 0.993 & 0.803 \\
\hline 9 & & CD8 & 0.51 & 84.60 & 1.877 & 1.084 & 1.024 & 0.986 & 0.953 \\
\hline 10 & [23] & Control & 0.30 & 111.57 & 0.994 & 0.823 & 0.849 & 1.080 & 1.139 \\
\hline 11 & [24] & SPB & 0.25 & 150.00 & 1.350 & 1.145 & 1.132 & 1.274 & 1.574 \\
\hline 12 & \multirow{3}{*}[25]{} & S1 & 0.30 & 83.10 & 1.331 & 1.322 & 1.239 & 1.114 & 1.086 \\
\hline 13 & & $\mathrm{~S} 2$ & 0.50 & 74.80 & 1.511 & 1.744 & 1.741 & 1.568 & 1.184 \\
\hline 14 & & S3 & 0.30 & 121.50 & 1.832 & 1.537 & 1.371 & 1.226 & 1.358 \\
\hline 15 & {$[26]$} & IP3C & 0.25 & 35.80 & 1.512 & 1.430 & 1.507 & 0.989 & 1.099 \\
\hline 16 & {$[27]$} & $\mathrm{C} 0$ & 0.30 & 111.56 & 1.175 & 1.179 & 1.666 & 1.338 & 1.029 \\
\hline 17 & \multirow{3}{*}[28]{} & H9 & 0.31 & 33.00 & 1.414 & 1.267 & 1.297 & 1.007 & 0.984 \\
\hline 18 & & $\mathrm{H} 10$ & 0.32 & 36.10 & 1.572 & 1.119 & 1.079 & 0.929 & 0.964 \\
\hline 19 & & H11 & 0.64 & 25.20 & 2.039 & 1.346 & 1.332 & 1.147 & 0.891 \\
\hline 20 & [29] & S4 & 0.08 & 35.50 & 0.790 & 0.851 & 0.981 & 1.081 & 1.288 \\
\hline
\end{tabular}




\begin{tabular}{|c|c|c|c|c|c|c|c|c|c|}
\hline 21 & & S5 & 0.16 & 37.50 & 0.890 & 0.975 & 1.106 & 1.243 & 1.344 \\
\hline 22 & \multirow{2}{*}{ [30] } & AP1 & 0.35 & 52.06 & 0.866 & 0.878 & 0.763 & 0.750 & 0.743 \\
\hline 23 & & AP3 & 0.22 & 86.77 & 1.236 & 1.186 & 1.033 & 0.718 & 0.807 \\
\hline 24 & \multirow{2}{*}{ [31] } & RCA & 0.44 & 70.70 & 1.208 & 0.898 & 1.039 & 0.896 & 0.800 \\
\hline 25 & & RCB & 0.41 & 81.25 & 0.994 & 0.865 & 1.031 & 0.893 & 0.743 \\
\hline 26 & [32] & RI-50 & 0.37 & 91.64 & 1.376 & 1.639 & 2.041 & 1.282 & 1.368 \\
\hline 27 & \multirow{5}{*}{ [33] } & ND1C & 0.24 & 42.39 & 0.719 & 0.775 & 0.927 & 0.944 & 0.946 \\
\hline 28 & & ND4LL & 0.35 & 44.45 & 0.845 & 0.996 & 1.189 & 1.108 & 1.154 \\
\hline 29 & & ND5XL & 0.45 & 32.52 & 0.852 & 0.990 & 1.125 & 1.116 & 1.002 \\
\hline 30 & & ND6HR & 0.28 & 58.58 & 1.114 & 0.906 & 0.980 & 1.189 & 1.190 \\
\hline 31 & & ND7LR & 0.33 & 29.91 & 0.730 & 0.871 & 1.060 & 0.960 & 1.038 \\
\hline 32 & [34] & $1 \mathrm{C}$ & 0.25 & 58.30 & 0.999 & 1.005 & 1.147 & 1.223 & 1.173 \\
\hline 33 & [35] & C-02 & 0.38 & 44.61 & 0.935 & 0.819 & 0.692 & 0.612 & 0.602 \\
\hline 34 & [36] & INT & 0.30 & 10.27 & 1.388 & 1.252 & 1.027 & 0.971 & 1.095 \\
\hline 35 & \multirow{3}{*}{ [38] } & C-30 & 0.28 & 121.60 & 1.134 & 1.007 & 1.040 & 1.029 & 1.043 \\
\hline 36 & & C-40 & 0.39 & 102.80 & 1.257 & 1.073 & 1.083 & 1.072 & 0.981 \\
\hline 37 & & C-50 & 0.49 & 74.80 & 1.102 & 0.967 & 0.953 & 0.943 & 0.767 \\
\hline 38 & \multirow{4}{*}{ [39] } & H.H.H.C.0.5 & 0.25 & 134.47 & 1.108 & 1.374 & 1.638 & 1.067 & 1.677 \\
\hline 39 & & H.H.H.C.1.0 & 0.25 & 162.97 & 1.385 & 1.216 & 1.246 & 1.219 & 1.359 \\
\hline 40 & & N.H.H.C.0.5 & 0.35 & 100.48 & 1.385 & 1.529 & 1.681 & 1.279 & 1.412 \\
\hline 41 & & N.H.H.C.1.0 & 0.36 & 127.24 & 1.807 & 1.347 & 1.319 & 1.288 & 1.355 \\
\hline 42 & \multirow{6}{*}[40]{} & HSLW0.5C & 0.26 & 135.80 & 1.180 & 1.445 & 1.707 & 1.128 & 1.714 \\
\hline 43 & & HSLW1.0C & 0.26 & 174.00 & 1.512 & 1.318 & 1.347 & 1.318 & 1.473 \\
\hline 44 & & NSLW0.5C & 0.36 & 116.20 & 1.664 & 1.821 & 1.991 & 1.535 & 1.639 \\
\hline 45 & & NSLW1.0C & 0.36 & 151.70 & 2.172 & 1.614 & 1.580 & 1.543 & 1.623 \\
\hline 46 & & NSNW0.5C & 0.36 & 132.37 & 1.895 & 2.075 & 2.268 & 1.749 & 1.867 \\
\hline 47 & & NSNW1.0C & 0.36 & 176.40 & 2.526 & 1.877 & 1.837 & 1.795 & 1.889 \\
\hline
\end{tabular}




\begin{tabular}{|c|c|c|c|c|c|c|c|c|c|}
\hline 48 & [41] & $8 \mathrm{I}$ & 0.18 & 60.15 & 1.010 & 0.990 & 0.861 & 0.998 & 1.035 \\
\hline 49 & [42] & $\mathrm{RC} 1$ & 0.40 & 80.75 & 0.985 & 0.859 & 0.882 & 0.761 & 0.660 \\
\hline 50 & [43] & SC0 & 0.25 & 62.03 & 0.997 & 0.915 & 0.796 & 0.934 & 0.985 \\
\hline \multicolumn{5}{|c|}{ Mean } & 1.424 & 1.212 & 1.257 & 1.141 & 1.150 \\
\hline \multicolumn{5}{|c|}{ St Dev } & 0.583 & 0.312 & 0.345 & 0.243 & 0.303 \\
\hline \multicolumn{5}{|c|}{$\mathrm{COV}$} & 0.410 & 0.258 & 0.274 & 0.213 & 0.263 \\
\hline
\end{tabular}


Table A3. Summary of measured to predicted drift or $\psi_{s c c}$ from slab database

\begin{tabular}{|c|c|c|c|c|c|c|c|c|c|c|}
\hline \multirow[b]{2}{*}{ No } & \multirow[b]{2}{*}{ Source } & \multirow[b]{2}{*}{ Specimen } & \multirow[b]{2}{*}{ GSR } & \multirow[b]{2}{*}{ Measured drift or $\psi_{s c c}(\%)$} & \multicolumn{6}{|c|}{ Measured/Predicted drift or $\psi_{\text {scc }}(\%)$ at peak unbalanced moment } \\
\hline & & & & & $\begin{array}{c}\text { ACI 318- } \\
14\end{array}$ & $\begin{array}{c}\text { Megally } \\
\text { and Ghali }\end{array}$ & $\begin{array}{c}\text { Hueste and } \\
\text { Wight }\end{array}$ & $\begin{array}{c}\text { CSCT with } \\
\text { original } k_{e} \\
\text { formulation }\end{array}$ & $\begin{array}{c}\text { Proposed } \\
\text { method }\end{array}$ & $\begin{array}{c}\text { Drakatos } \\
\text { et al. } \\
\text { method }\end{array}$ \\
\hline 1 & \multirow{5}{*}[10]{} & PD2 & 0.778 & $0.36^{*}$ & 0.720 & 0.487 & 0.414 & 0.973 & 0.946 & 1.248 \\
\hline 2 & & PD6 & 0.535 & $0.86^{*}$ & 1.040 & 0.767 & 0.674 & 1.375 & 1.342 & 1.358 \\
\hline 3 & & PD8 & 0.424 & $1.30 *$ & 0.941 & 0.896 & 0.890 & 1.737 & 1.661 & 1.596 \\
\hline 4 & & PD11 & 0.833 & $0.43 *$ & 0.860 & 0.628 & 0.553 & 1.305 & 1.264 & 1.627 \\
\hline 5 & & PD13 & 0.559 & $0.86^{*}$ & 1.218 & 0.806 & 0.696 & 1.841 & 1.760 & 1.638 \\
\hline 6 & [11] & L0.5 & 0.230 & 2.00 & 0.851 & 0.699 & 0.552 & 0.986 & 0.802 & 0.774 \\
\hline 7 & \multirow{3}{*}[22]{} & CD1 & 0.843 & 0.87 & 1.748 & 1.293 & 1.148 & 1.381 & 1.331 & 1.303 \\
\hline 8 & & CD5 & 0.640 & 1.22 & 2.430 & 1.323 & 1.104 & 1.490 & 1.444 & 1.493 \\
\hline 9 & & CD8 & 0.510 & 1.39 & 1.466 & 1.179 & 1.058 & 1.226 & 1.137 & 1.340 \\
\hline 10 & [23] & Control† & 0.299 & 4.44 & 2.212 & 2.074 & 1.604 & 2.181 & 2.611 & 2.368 \\
\hline 11 & [24] & $\mathrm{SPB} \dagger$ & 0.250 & 3.69 & 1.640 & 1.416 & 1.093 & 1.336 & 1.425 & 1.331 \\
\hline 12 & \multirow{3}{*}[25]{} & S1 & 0.300 & 3.00 & 1.501 & 1.410 & 1.092 & 1.207 & 1.010 & 1.052 \\
\hline 13 & & S2 & 0.500 & 3.00 & 3.001 & 2.485 & 2.250 & 1.783 & 1.614 & 1.450 \\
\hline 14 & & S3 & 0.300 & 3.00 & 1.500 & 1.409 & 1.091 & 1.364 & 1.130 & 1.127 \\
\hline 15 & [26] & IP3C & 0.246 & 3.62 & 1.596 & 1.367 & 1.059 & 1.631 & 0.812 & 0.979 \\
\hline 16 & [27] & $\mathrm{CO}$ & 0.302 & 2.80 & 1.408 & 1.326 & 1.029 & 2.074 & 1.532 & 1.468 \\
\hline 17 & \multirow{3}{*}{ [28] } & H9 & 0.313 & 2.00 & 1.032 & 0.983 & 0.771 & 1.195 & 0.858 & 0.799 \\
\hline 18 & & H10 & 0.324 & 2.00 & 1.063 & 1.023 & 0.816 & 1.593 & 1.297 & 1.042 \\
\hline 19 & & H11 & 0.639 & 1.00 & 2.000 & 1.088 & 0.908 & 1.075 & 0.932 & 0.916 \\
\hline 20 & \multirow{2}{*}{ [29] } & $\mathrm{S} 4 \dagger$ & 0.081 & 4.50 & 1.455 & 0.496 & 0.821 & 0.978 & 1.094 & 0.801 \\
\hline 21 & & $\mathrm{~S} 5 \dagger$ & 0.159 & 4.80 & 1.774 & 1.114 & 1.063 & 1.119 & 1.266 & 1.063 \\
\hline
\end{tabular}




\begin{tabular}{|c|c|c|c|c|c|c|c|c|c|c|}
\hline 22 & \multirow{2}{*}{ [30] } & $\mathrm{AP} 1 \dagger$ & 0.351 & 1.60 & 0.918 & 0.895 & 0.758 & 0.495 & 0.490 & 0.577 \\
\hline 23 & & AP3 & 0.220 & 3.17 & 1.320 & 1.056 & 0.845 & 0.936 & 0.548 & 0.654 \\
\hline 24 & \multirow{2}{*}[31]{} & RCA & 0.442 & 1.34 & 1.040 & 0.968 & 0.937 & 1.417 & 1.220 & 1.195 \\
\hline 25 & & $\mathrm{RCB}$ & 0.406 & 1.44 & 0.980 & 0.947 & 0.967 & 1.274 & 1.114 & 1.101 \\
\hline 26 & [32] & RI-50† & 0.370 & 3.44 & 2.086 & 2.040 & 1.836 & 1.793 & 1.168 & 1.197 \\
\hline 27 & \multirow{5}{*}{ [33] } & ND1C $†$ & 0.237 & 3.00 & 1.295 & 1.084 & 0.847 & 1.085 & 1.099 & 1.112 \\
\hline 28 & & ND4LL $\dagger$ & 0.348 & 3.00 & 1.705 & 1.663 & 1.397 & 1.391 & 1.254 & 1.293 \\
\hline 29 & & ND5XL $\dagger$ & 0.452 & 2.00 & 1.615 & 1.482 & 1.416 & 1.272 & 1.260 & 1.168 \\
\hline 30 & & ND6HR $\dagger$ & 0.278 & 3.00 & 1.421 & 1.293 & 0.990 & 1.522 & 2.048 & 1.913 \\
\hline 31 & & ND7LR $\dagger$ & 0.335 & 3.00 & 1.643 & 1.591 & 1.295 & 1.433 & 1.254 & 1.239 \\
\hline 32 & [34] & $1 \mathrm{C}^{\dagger}$ & 0.247 & 3.50 & 1.544 & 1.323 & 1.024 & 1.336 & 1.398 & 1.412 \\
\hline 33 & [35] & C-02 & 0.381 & 2.44 & 1.530 & 1.494 & 1.404 & 1.064 & 0.844 & 0.987 \\
\hline 34 & [36] & $\mathrm{INT}^{\dagger}$ & 0.302 & 3.81 & 1.911 & 1.800 & 1.396 & 1.245 & 1.198 & 1.212 \\
\hline 35 & \multirow{3}{*}{ [38] } & C-30 & 0.278 & 2.00 & 0.948 & 0.864 & 0.661 & 1.071 & 1.053 & 0.929 \\
\hline 36 & & $\mathrm{C}-40$ & 0.392 & 1.50 & 0.975 & 0.949 & 0.940 & 1.115 & 1.099 & 1.085 \\
\hline 37 & & C-50 & 0.485 & 1.10 & 1.025 & 0.881 & 0.810 & 0.969 & 0.957 & 0.963 \\
\hline 38 & \multirow{4}{*}{ [39] } & H.H.Н.C.0.5 & 0.245 & $3.95 *$ & 1.737 & 1.484 & 1.150 & 1.220 & 0.811 & 0.852 \\
\hline 39 & & H.H.H.C.1.0 & 0.251 & $3.56^{*}$ & 1.586 & 1.372 & 1.059 & 1.326 & 1.310 & 1.255 \\
\hline 40 & & N.H.H.C.0.5 & 0.352 & $3.43 *$ & 1.972 & 1.925 & 1.635 & 1.726 & 1.116 & 1.253 \\
\hline 41 & & N.H.H.C.1.0 & 0.359 & $2.45^{*}$ & 1.437 & 1.405 & 1.217 & 1.036 & 1.026 & 1.474 \\
\hline 42 & \multirow{6}{*}[40]{} & HSLW0.5C & 0.255 & $4.70^{*}$ & 2.113 & 1.845 & 1.420 & 1.528 & 0.999 & 1.091 \\
\hline 43 & & HSLW1.0C & 0.255 & $3.20 *$ & 1.439 & 1.256 & 0.967 & 1.200 & 1.185 & 1.153 \\
\hline 44 & & NSLW0.5C & 0.361 & $4.60^{*}$ & 2.713 & 2.653 & 2.313 & 2.395 & 1.588 & 1.673 \\
\hline 45 & & NSLW1.0C & 0.361 & $3.30 *$ & 1.946 & 1.903 & 1.659 & 1.398 & 1.384 & 1.977 \\
\hline 46 & & NSNW0.5C & 0.361 & $3.70^{*}$ & 2.182 & 2.134 & 1.860 & 1.926 & 1.277 & 1.346 \\
\hline 47 & & NSNW1.0C & 0.361 & $3.50 *$ & 2.064 & 2.018 & 1.760 & 1.483 & 1.468 & 2.096 \\
\hline 48 & {$[41]$} & $8 \mathrm{I} \dagger$ & 0.178 & 3.50 & 1.342 & 0.922 & 0.819 & 1.005 & 1.120 & 0.956 \\
\hline
\end{tabular}




\begin{tabular}{|c|c|c|c|c|c|c|c|c|c|c|}
\hline 49 & [42] & $\mathrm{RC} 1$ & 0.400 & 1.40 & 0.933 & 0.905 & 0.933 & 1.085 & 0.911 & 0.865 \\
\hline 50 & [43] & $\mathrm{SC} 0 \dagger$ & 0.247 & 3.50 & 1.547 & 1.328 & 1.027 & 1.166 & 1.296 & 1.186 \\
\hline \multicolumn{5}{|c|}{ Mean (without 0.22L slab contribution) } & $\mathbf{1 . 5 2 8}$ & $\mathbf{1 . 3 1 5}$ & 1.121 & $\mathbf{1 . 3 5 5}$ & $\mathbf{1 . 2 1 5}$ & 1.240 \\
\hline \multicolumn{5}{|c|}{ Standard Deviation (without 0.22L slab contribution) } & 0.495 & 0.483 & 0.405 & 0.350 & 0.349 & 0.355 \\
\hline \multicolumn{5}{|c|}{ Coefficient of Variation (COV) (without 0.22L slab contribution) } & 0.324 & 0.367 & 0.362 & 0.258 & 0.287 & 0.287 \\
\hline \multicolumn{5}{|c|}{ "Mean (with 0.22L slab contribution) } & $\mathbf{1 . 5 2 8}$ & $\mathbf{1 . 3 1 5}$ & 1.121 & 1.297 & $\mathbf{1 . 1 5 5}$ & $\mathbf{1 . 1 8 3}$ \\
\hline \multicolumn{5}{|c|}{ Standard Deviation (with 0.22L slab contribution) } & 0.495 & 0.483 & 0.405 & 0.356 & 0.315 & 0.343 \\
\hline \multicolumn{5}{|c|}{ Coefficient of Variation (COV) (with 0.22L slab contribution) } & 0.324 & 0.367 & 0.362 & 0.274 & 0.273 & 0.290 \\
\hline
\end{tabular}

Notes:

* indicates specimen where $\boldsymbol{\psi}_{s c c}$ is measured from experimental test

+ indicates specimen where drift is calculated as $\psi_{\text {scc }} / 0.85$ to consider the contribution of slab rotation outside 0.22L for CSCT based methods 